\title{
Modelling Emerging Market Risk Premia Using Higher Moments
}

Soosung Hwang and Stephen Satchell 


\title{
Modelling Emerging Market Risk Premia Using Higher
}

\author{
Moments \\ Soosung Hwang \\ Department of Applied Economics, University of Cambridge \\ Stephen E. Satchell ${ }^{1}$ \\ Faculty of Economics and Politics and Trinity College, \\ University of Cambridge
}

August 11, 1999

\footnotetext{
${ }^{1}$ The authors thank anonymous referees for very helpful remarks. The first author would like to thank the Newton Trust and Dresdner Kleinwort Benson for financial support. The second author would like to thank Inquire for financial support.
} 


\begin{abstract}
The purpose of this paper is to assess the incremental value of higher moments in modelling CAPMs of emerging markets. Whilst it is recognised that emerging markets are unlikely to yield sensible results in a mean-variance world, the high skewness and kurtosis present in emerging markets returns make our assessment potentially interesting. Generalized method of moments (GMM) is used for the estimation. We also present new versions of higher-moment market models of the data generating process of the individual emerging markets and use these to identify model parameters. We find some evidence that emerging markets are better explained with additional systematic risks such as co-skewness and co-kurtosis than the conventional mean-variance CAPM.
\end{abstract}

Keywords: CAPM, Data Generating Process, Emerging Markets, Higher Moments, Kurtosis, Skewness.

JEL Classification: D81, G11, G12 


\section{SUMMARY}

Many empirical studies on emerging markets suggest that methods of conventional finance such as the mean-variance CAPM are highly misleading when applied to pricing assets. There are many explanations given; non-stationarity due to evolving degrees of market integration, the importance of non-economic factors such as political risk, the presence of survivorship and re-emerging bias in emerging markets data; country selection bias, and the evolution from an emerging market to a mature one.

In this study, we focus on the highly significant skewness and kurtosis prevalent in emerging markets data. The question we explore in this study is whether emerging markets may be better explained with additional risk factors such as higher moments, e.g., skewness and kurtosis. We develop higher moment CAPMs, and test them using generalized method of moments since the distribution function of emerging markets return is not known. Our empirical results show that emerging markets are better explained with higher-moments CAPMs. In addition, co-kurtosis has at least as much explanatory power as co-skewness for the countries used in this study.

In addition, we also use an alternative approach using data generating processes conditioning on the market as in Sharpe's market model. This is because the high multicollinearity in sample co-moments seems to make it hard to jointly estimate co-skewness and co-kurtosis. To reduce these difficulties, specific models are introduced as candidate data generating processes; these are the quadratic and cubic market models. We show that higher-moment data generating processes are consistent with higher-moment CAPMs, and empirical tests reveal that the collinearity in the parameters appears to be reduced.

We note that whilst the use of higher moments seems to explain emerging markets better than conventional CAPMs, the higher-moment CAPMs are based on an assumption of stationarity in emerging market returns. Since there is clear evolution in these markets, 
our basic assumption is probably inappropriate. In future research, we hope to investigate this problem further by combining the ideas of this paper with the evolving models of Bekaert and Harvey (1995). 


\section{INTRODUCTION}

Research on emerging markets investment has identified the following features; high returns, high volatility, low correlation between emerging and mature markets and low correlation between emerging markets which has increased through time. Much of the research has concentrated on the question of the usefulness of conventional finance to price assets in emerging markets. The results suggest that the mean-variance CAPM is highly misleading and that a capitalization weighted portfolio seriously underperforms such simple constructs as an equally weighted portfolio, for example.

Explanations for the theoretical shortcomings involve non-stationarity due to, for example, evolving degrees of market integration, the importance of non-economic factors, such as political risk, and the inadequacy of two-fund separation and representative agent based arguments. Bekaert, Erb, Harvey, and Viskanta (1997) discuss the above and also present other explanations concerned with the nature of data; the presence of survivorship bias, the data are chosen over a short period, the data miss the longer period of earlier failure (re-emerging bias); there is also the presence of country selection bias. Other references for the above discussion are numerous. Results on portfolio evaluation can be found in Masters (1998).

It is probably unlikely that any version of the CAPM will work in these markets. One reason may be due to liberalisation within the sample period such that a local CAPM was valid before the structural break and a world CAPM was valid after the break, see Bekaert and Harvey $(1995,1997)$. More recently some markets, i.e., Malaysia, have been trying to engineer a reverse process, referred to as submerging markets. All in all, a conventional model will face difficulties.

It is likely that one cannot model risk premia in those markets without including political/social variables. However, we are not aware of much modelling work that uses the 
highly significant skewness and kurtosis prevalent in emerging markets data; see for example, Bekaert, Erb, Harvey, and Viskanta (1998) for the evidence of significant skewness and kurtosis in these markets. Since there exists a literature on the incorporation of higher moments into risk premia, see Arditti (1967), Jean (1971, 1973), Ingersoll (1975), Kraus and Litzenberger (1976), Friend and Westfield (1980), Sears and Wei (1985, 1988), Homaifar and Graddy (1988), and Lim (1989), it seems worthwhile to explore this modelling strategy, if only to eliminate it as a potential explanation. Therefore, throughout this study, we implicitly assume that higher-moments of returns exist; for the three-moment CAPMs, the first three moments are assumed to exist and for the four-moment CAPMs, the first four moments are assumed to exist.

Although a theory of asset pricing using co-skewness is well-known, a theory involving co-skewness and co-kurtosis is not. Homaifar and Graddy (1988) derive a higher moment CAPM with Sharpe's (1964) methodology and test the higher moment CAPM using principal component regression, latent root regression, and ordinary least square regression. In this paper we develop higher moment CAPMs in a different way, see section 1, and test them using Hansen's (1982) generalized method of moments (GMM). To implement and estimate these models, certain marginal rates of substitution between different moments need to be identified. We achieve this by considering (a) quartic approximations to utility functions, (b) logarithmic utility; these calculations extend existing results in the non-normal CAPM literature.

In section 2, we describe our data and estimation technique. Following Lim (1989), we use a multivariate approach with generalized method of moments (GMM). This procedure is known to be consistent but inefficient relative to maximum likelihood. However, it has the important property of being implementable without having to specify the data generating process (DGP) for returns. It also avoids the measurement error problem present in tra- 
ditional cross-sectional asset pricing model such as Kraus and Litzenberger (1976), Friend and Westfield (1980), Sears and Wei (1988), Homaifar and Graddy (1988).

There is enormous difficulty in assessing the correct data generating process for emerging market returns. Our results reflect the difficulty of modelling returns in these markets; skewness and kurtosis move in a collinear manner with the market. To reduce these difficulties, specific models are introduced as candidate DGPs in section 3; these are the quadratic and cubic market models. Assuming that the data are generated by these processes implies specific restrictions for the higher moment CAPMs which are presented in Theorem 4; these results are new to the literature. The relationship between the higher-moment CAPMs and the higher-moment market models is investigated and the higher-moment market models are estimated for the emerging markets. We present conclusions in section 4.

\section{HIGHER-MOMENT CAPMs}

In this section, we present various versions of the higher-moment CAPM. It is assumed that there is a representative (mature-market) investor, and that all returns are in units of period 1 consumption. We suppose that there is a riskless asset whose return is $r_{f}$ and $N$ risky assets whose $i$ th return is represented as $r_{i}$. Investment proportions on the riskless asset and the $N$ risky assets are $x_{0}$ and $x_{i}(i=1,2,3, \ldots, N)$, where $x_{0}+\sum_{i=1}^{N} x_{i}=1$. We assume that for the investor, the initial investment is 1 and the end of period wealth is represented as $w$. Then the end of period wealth is

$$
w=x_{0}\left(1+r_{f}\right)+\sum_{i=1}^{N} x_{i}\left(1+r_{i}\right)
$$

Note that the portfolio return for the investor is $r_{p}=x_{0} r_{f}+\sum_{i=1}^{N} x_{i} r_{i}$.

The first four moments of the end of period wealth and their relationship with systematic risk measures (i.e., beta, systematic skewness, and systematic kurtosis) can be derived as in 
Kraus and Litzenberger (1976) (see Appendix 1). That is, if we define the systematic risk measures, $\beta_{i p}, \gamma_{i p}$, and $\theta_{i p}$ as

$$
\begin{aligned}
\beta_{i p} & =\frac{E\left[\left\{r_{i}-E\left(r_{i}\right)\right\}\left\{r_{p}-E\left(r_{p}\right)\right\}\right]}{E\left[\left\{r_{p}-E\left(r_{p}\right)\right\}^{2}\right]} \\
\gamma_{i p} & =\frac{E\left[\left\{r_{i}-E\left(r_{i}\right)\right\}\left\{r_{p}-E\left(r_{p}\right)\right\}^{2}\right]}{E\left[\left\{r_{p}-E\left(r_{p}\right)\right\}^{3}\right]} \\
\theta_{i p} & =\frac{E\left[\left\{r_{i}-E\left(r_{i}\right)\right\}\left\{r_{p}-E\left(r_{p}\right)\right\}^{3}\right]}{E\left[\left\{r_{p}-E\left(r_{p}\right)\right\}^{4}\right]}
\end{aligned}
$$

then it follows that

$$
\sigma(w)=\sum_{i=1}^{N} x_{i} \beta_{i p} \sigma\left(r_{p}\right)
$$

where $\sigma(z)=E\left[\{z-E(z)\}^{2}\right]^{1 / 2}$,

$$
\gamma(w)=\sum_{i=1}^{N} x_{i} \gamma_{i p} \gamma\left(r_{p}\right)
$$

where $\gamma(z)=E\left[\{z-E(z)\}^{3}\right]^{1 / 3}$, and

$$
\theta(w)=\sum_{i=1}^{N} x_{i} \theta_{i p} \theta\left(r_{p}\right)
$$

where $\theta(z)=E\left[\{z-E(z)\}^{4}\right]^{1 / 4}$ and $z$ is a random variable ( we note that the above parameters all have the property that they are homogeneous of degree 1 in $x$ ). The measures, $\beta_{i p}, \gamma_{i p}$, and $\theta_{i p}$, are known as beta, systematic skewness and systematic kurtosis and, as we shall see, are natural measures of systematic risk, or exposure, of an asset to market variance, skewness and kurtosis. Here we use the subscript $p$ to refer to the portfolio of interest. Throughout this study, $\sigma(z), \gamma(z)$, and $\theta(z)$ are called as standard deviation, skewness, and kurtosis. Note that skewness and kurtosis are generally defined as $E\left[\{z-E(z)\}^{3}\right] / \sigma(z)^{3}$ and $E\left[\{z-E(z)\}^{4}\right] / \sigma(z)^{4}$, respectively. In this study we call these expressions 'normalised skewness' and 'normalised kurtosis' to separate them from our definitions in (6) and (7) . 
The investment problem is described next; the investor maximizes the expected utility of end of period wealth subject to a budget constraint as follows:

$$
\begin{aligned}
\operatorname{Max} E[U(w)] & =f(E(w), \sigma(w), \gamma(w), \theta(w)) \\
\text { subject to } 1 & =x_{0}+\sum_{i=1}^{N} x_{i}
\end{aligned}
$$

Taking the first order conditions for the Lagrangian which is formed for the above maximization problem and solving for the investor's equilibrium condition, we obtain the following equation (see Appendix 2).

$$
E\left(r_{i}\right)-r_{f}=\left[\frac{d E(w)}{d \sigma(w)}\right] \beta_{i p} \sigma\left(r_{p}\right)+\left[\frac{d E(w)}{d \gamma(w)}\right] \gamma_{i p} \gamma\left(r_{p}\right)+\left[\frac{d E(w)}{d \theta(w)}\right] \theta_{i p} \theta\left(r_{p}\right)
$$

In order to move from the individual equilibrium model to a market equilibrium model, we need a portfolio separation theorem. Under this theorem, all individual investors maximize their utility with two funds; a riskless asset and the market portfolio. This is referred to as two fund money separation (TFMS). Conditions which ensure TFMS are that all agents have a hyperbolic absolute risk aversion (HARA) utility with the same "cautiousness" parameter. In this case, the individual investor's optimum portfolio composition is equivalent to that of the market portfolio. Therefore, equation (9) becomes

$$
E\left(r_{i}\right)-r_{f}=\left[\frac{d E(w)}{d \sigma(w)}\right] \beta_{i m} \sigma\left(r_{m}\right)+\left[\frac{d E(w)}{d \gamma(w)}\right] \gamma_{i m} \gamma\left(r_{m}\right)+\left[\frac{d E(w)}{d \theta(w)}\right] \theta_{i m} \theta\left(r_{m}\right)
$$

where $r_{m}$ is the rate of return on the market portfolio. We present the above result as theorem 1.

Theorem 1 The four-moment CAPM can be represented as

$$
E\left(r_{i}\right)-r_{f}=\alpha_{1} \beta_{i m}+\alpha_{2} \gamma_{i m}+\alpha_{3} \theta_{i m}
$$

where $\alpha_{1}=\frac{d E(w)}{d \sigma(w)} \sigma\left(r_{m}\right), \alpha_{2}=\frac{d E(w)}{d \gamma(w)} \gamma\left(r_{m}\right)$ and $\alpha_{3}=\frac{d E(w)}{d \theta(w)} \theta\left(r_{m}\right)$.

Proof. See above. 
Remark 1 We expect the market price of beta reduction, $\alpha_{1}$, to be positive as in the conventional CAPM. On the other hand, the market price of co-skewness, $\alpha_{2}$, should be negative (positive) when $\gamma\left(r_{m}\right)>0\left(\gamma\left(r_{m}\right)<0\right)$, since $\frac{d E(w)}{d \gamma(w)}=-\frac{\partial E[U(w)] / \partial \gamma(w)}{\partial E[U(w)] / \partial E(w)}<0$ under nonincreasing absolute risk aversion, see equations (15) and (17). Therefore, $\alpha_{2}$ is expected to have the opposite sign as $\gamma\left(r_{m}\right)$, see Kraus and Litzenberger (1976). Finally, the market price of co-kurtosis, $\alpha_{3}$, is expected to be positive, since $\frac{d E(w)}{d \theta(w)}=-\frac{\partial E[U(w)] / \partial \theta(w)}{\partial E[U(w)] / \partial E(w)}>0$, see equations (15) and (18). That is, the positive $\alpha_{3}$ is an additional measure of degree of dispersion in returns and thus should have the similar explanation to $\alpha_{1}$.

Remark 2 If $\alpha_{3}=0$, we have the Kraus and Litzenberger (19\%6) (KL) three-moment CAPM. We refer to equation (11) as the KL four-moment CAPM.

It is important to note that equation (11) has been derived without any assumptions abut the DGP generating returns. Indeed this section is written consciously trying to avoid specifying a model for emerging market returns. Authors notably, Kraus and Litzenberger (1976, 1983), have specified a DGP relating $r_{i}$ to a quadratic conditional expectation function (CEF) in $r_{m}$. This can then be used to make inferences about co-skewness. Likewise, if we were to add a cubic CEF, we could model co-kurtosis. Such an approach will be left to section 3.

Empirical results on the three-moment CAPM are not consistent: KL found significant coefficients on beta and co-skewness, while Friend and Westerfield (1980) did not. Sears and Wei (1985) argued that the empirical value of market risk premium, $E\left(r_{m}\right)-r_{f}$, can affect the estimation of asset pricing models, that is, coefficients on beta and co-skewness. When we apply equation (10) to the market portfolio, we obtain the following equation.

$$
E\left(r_{m}\right)-r_{f}=\left[\frac{d E(w)}{d \sigma(w)}\right] \sigma\left(r_{m}\right)+\left[\frac{d E(w)}{d \gamma(w)}\right] \gamma\left(r_{m}\right)+\left[\frac{d E(w)}{d \theta(w)}\right] \theta\left(r_{m}\right)
$$


since $\beta_{i m}=\gamma_{i m}=\theta_{i m}=1$ when $i$ is the market portfolio. Dividing equation (10) by equation (12), we present as a corollary to theorem 1 the Sears and Wei (1985) version of the four-moment CAPM.

Corollary 2 The Sears and Wei (1985) (SW) four-moment CAPM is represented as

$$
E\left(r_{i}\right)-r_{f}=\left(b_{1} \beta_{i m}+b_{2} \gamma_{i m}+b_{3} \theta_{i m}\right)\left(E\left(r_{m}\right)-r_{f}\right)
$$

where $b_{1}=\frac{\sigma\left(r_{m}\right)}{\sigma\left(r_{m}\right)+k_{1} \gamma\left(r_{m}\right)+k_{2} \theta\left(r_{m}\right)}, b_{2}=\frac{k_{1} \gamma\left(r_{m}\right)}{\sigma\left(r_{m}\right)+k_{1} \gamma\left(r_{m}\right)+k_{2} \theta\left(r_{m}\right)}, b_{3}=\frac{k_{2} \theta\left(r_{m}\right)}{\sigma\left(r_{m}\right)+k_{1} \gamma\left(r_{m}\right)+k_{2} \theta\left(r_{m}\right)}$, $k_{1}=\frac{d E(w) / d \gamma(w)}{d E(w) / d \sigma(w)}$, and $k_{2}=\frac{d E(w) / d \theta(w)}{d E(w) / d \sigma(w)}$.

Remark 3 If $k_{2}=0$, we have the $S W$ three-moment CAPM.

Here, $k_{1}$ is interpreted as the market's marginal rate of substitution between skewness and risk and $k_{2}$ is the market's marginal rate of substitution between kurtosis and risk. Therefore, the coefficients of KL models have the following relationship with those of SW models: $\alpha_{1}=b_{1}\left(E\left(r_{m}\right)-r_{f}\right)$ and $\alpha_{2}=b_{2}\left(E\left(r_{m}\right)-r_{f}\right)$.

Theoretically, the market risk premium is always positive. However, in practice, there may be a period when the sample value of the market risk premium has a negative sign. SW argue that the tests of asset pricing model may be affected by the sign of the market risk premium. These formulae depend upon the assumption that equation (11) holds for the market as well, which will be discussed later.

For the SW four-moment CAPM in equation (13), we further investigate the marginal rates of substitution. The investor's expected utility of end of period wealth function may be approximated as follows using a Taylor series about $E(w)$ :

$$
\begin{aligned}
E[U(w)] \approx & U(E(w))+\frac{U^{\prime \prime}(E(w))}{2 !} \sigma(w)^{2} \\
& +\frac{U^{\prime \prime \prime}(E(w))}{3 !} \gamma(w)^{3}+\frac{U^{\prime \prime \prime}(E(w))}{4 !} \theta(w)^{4}
\end{aligned}
$$

The non-satiation and decreasing marginal utility conditions require $U^{\prime}(E(w))>0$ and $U^{\prime \prime}(E(w))<0$, respectively. In addition, the sufficient condition for the non-increasing 
absolute risk aversion is $U^{\prime \prime \prime}(E(w))>0$. Turning to preference for the fourth moment, Scott and Horvath (1980) show in Theorem 2 that $U^{\prime \prime \prime \prime}(E(w))<01$. Therefore, using these conditions, when we differentiate equation (14) with respect to $E(w), \sigma(w), \gamma(w), \theta(w)$, we obtain $^{2}$

$$
\begin{aligned}
& \frac{\partial E[U(w)]}{\partial E(w)} \approx U^{\prime}(E(w))>0 \\
& \frac{\partial E[U(w)]}{\partial \sigma(w)} \approx U^{\prime \prime}(E(w)) \sigma(w)<0 \\
& \frac{\partial E[U(w)]}{\partial \gamma(w)} \approx \frac{U^{\prime \prime \prime}(E(w))}{2 !} \gamma(w)^{2}>0 \\
& \frac{\partial E[U(w)]}{\partial \theta(w)} \approx \frac{U^{\prime \prime \prime \prime}(E(w))}{3 !} \theta(w)^{3}<0
\end{aligned}
$$

Note that the rates of the marginal substitution can be represented as $k_{1}=\frac{\partial E[U(w)] / \partial \gamma(w)}{\partial E[U(w)] / \partial \sigma(w)}$ and $k_{2}=\frac{\partial E[U(w)] / \partial \theta(w)}{\partial E[U(w)] / \partial \sigma(w)}$, using equations (A2.5), (A2.6), and (A2.7) in Appendix 2.

Remark 4 The marginal rates of substitution will have the following signs; $k_{1}<0$ and $k_{2}>0$.

Negative $k_{1}$ has the interpretation that rational investors prefer positive skewness and reduced risks. On the other hand, $k_{2}$ is positive, since investors dislike dispersion which both variance and kurtosis measure. As mentioned in Scott and Horvath (1980), $U^{\prime \prime \prime \prime}(E(w))<0$ may be explained in the same way as $U^{\prime \prime}(E(w))<0$. That is, investors dislike, in the above sense, dispersion of wealth for a given expected wealth. It therefore follows that in some situations, kurtosis may become an additional risk measure for assets which variance alone fails to explain.

For the four-moment CAPM, it seems to be difficult to identify $k_{1}$ and $k_{2}$. One solution is to use a known utility function which is parameter-free. One obvious candidate is logutility, $U(w)=\ln (w)$. In this case, we can represent the CAPM with skewness and kurtosis as follows (see Appendix 3);

$$
E\left(r_{i}\right)-r_{f}=\left(L_{1} \beta_{i m}+L_{2} \gamma_{i m}+L_{3} \theta_{i m}\right)\left(E\left(r_{m}\right)-r_{f}\right)
$$


where $L_{1}=\frac{E(w)^{2} \sigma\left(r_{m}\right)^{2}}{E(w)^{2} \sigma\left(r_{m}\right)^{2}-E(w) \gamma\left(r_{m}\right)^{3}+\theta\left(r_{m}\right)^{4}}, L_{2}=-\frac{E(w) \gamma\left(r_{m}\right)^{3}}{E(w)^{2} \sigma\left(r_{m}\right)^{2}-E(w) \gamma\left(r_{m}\right)^{3}+\theta\left(r_{m}\right)^{4}}$, and $L_{3}=$ $\frac{\theta\left(r_{m}\right)^{4}}{E(w)^{2} \sigma\left(r_{m}\right)^{2}-E(w) \gamma\left(r_{m}\right)^{3}+\theta\left(r_{m}\right)^{4}}$.

To summarize this section, we present seven models in table 1. In the following section, the estimation method for each model is described and results follow.

\section{EMPIRICAL TESTS}

All empirical tests in this paper are presented from an American investor' point of view. Returns of emerging markets are represented in dollars. For the riskless rate of return, we use the 3 month US treasury bill. As a proxy of the market portfolio, Morgan Stanley Capital International (MSCI) world index total returns are used. Our emerging market return series from the International Finance Corporation (IFC) global data set consist of 17 countries from January 1985 to January 1997 for a total of 145 observations. All of the above assumptions may involve difficulties, but they are standard.

Note that the rates of return on the riskless asset are not constant through time. As in KL, the observed excess rates of return on the individual countries deflated by unity plus the riskless interest rates, $R_{i t}=\left(r_{i t}-r_{f t}\right) /\left(1+r_{f t}\right)$, are used and the observed excess rates of return on the market portfolio are also deflated in the same way. This is a method to make moments of the rate of returns intertemporal constants under a changing riskless interest rate (see Fama, 1970). Under certain circumstances, it allows us to use one period models for time-series data.

Table 2 reports the first four moments of the data used in this study. As pointed out in Bekaert, Erb, Harvey, and Viskanta (1998), returns of the emerging markets are higher than the world market portfolio in 10 out of 17 emerging markets. In particular, all of the unconditional volatilities of the emerging markets are higher than that of the market 
portfolio. Consideration of the third and fourth moments shows that 14 out of 17 emerging markets are not normally distributed. Panel B of table 2 shows certain statistical properties of emerging markets when the market crash of October 1987 is excluded. The results are similar to those of panel A except for the market portfolio and Malaysia. This indirectly indicates that emerging market returns are not closely correlated with developed market returns. In addition, note that the number of significant coefficients of kurtosis is larger than the corresponding number of skewness coefficients. That is, the main source of nonnormality in emerging markets is kurtosis rather than skewness.

For the SW higher-moment CAPM we need the marginal rates of substitution. In the next subsection, we first estimate the marginal rates of substitution between risk and skewness and kurtosis for the American investor. Then the higher moment CAPMs will be estimated using emerging market data.

\subsection{Estimation of the Marginal Rates of Substitution}

A potential difficulty with our estimation is that the marginal rates of substitution, $k_{1}$ and $k_{2}$, inferred from the emerging markets data are wildly inaccurate measures of $k_{1}$ and $k_{2}$. Emerging market returns have quite different statistical properties from US asset returns and the marginal rates of substitution calculated from emerging market returns may be different from those calculated from domestic US data. If $k_{1}$ and $k_{2}$ are inferred from emerging markets, the estimates of the marginal rates of substitution are sensitive to the countries selected, since the first four moments of emerging markets are quite different across countries, see table 2. This means that the indirect utility function of the representative US investor inferred from our emerging market returns is likely to contaminate all our other results via the nonlinearity of the model. For these reasons, the marginal rates of substitution are estimated separately using a US data base rather than emerging markets data. This 
procedure assumes that American investors have the same marginal rates of substitution over domestic and overseas investment. It is only the moments that matter in the indirect utility function, not the location of the asset.

To reduce measurement errors in beta, co-skewness, and co-kurtosis, risk asset portfolios are formed with a grouping procedure similar to the procedures used by Kraus and Litzenberger (1976) and Sears and Wei (1988). We use monthly deflated excess returns on 273 US stocks in the MSCI world universe from January 1985 to January 1997. The S\&P 500 index total returns are used as a proxy of the market portfolio and the 3 month US treasury bill is used for the riskless rate of return.

First, we calculate systematic risks using 5 years monthly deflated excess returns. Then stocks are ranked into $N$-tiles ( $N$ groups) on the basis of beta estimates, and then for each group, stocks are ranked again into $N$-tiles on the basis of co-skewness estimates; therefore, the number of the risk asset portfolios for beta and co-skewness is $N^{2}$. In addition, for risk asset portfolios for beta, co-skewness, and co-kurtosis, stocks are ranked again into $N$-tiles on the basis of co-kurtosis estimates for each groups obtained for the risk asset portfolios of beta and co-skewness.. Therefore, the number of risk asset portfolios for beta, co-skewness, and co-kurtosis is $N^{3}$. The subsequent 12 months deflated excess returns for the risk portfolios are calculated for each group. This procedure is repeated for the entire sample period beginning each January. The final subsequent portfolio returns consist of 13 month returns from January 1996 to January 1997. This provides 85 monthly deflated excess returns from January 1990 to January 1997 for each of the $N^{2}$ (or $N^{3}$ ) portfolios.

To avoid a risk of spurious correlation between the systematic risks of the portfolios obtained above, the sample estimates of the systematic risks for the portfolios are calculated as follows, see Kraus and Litzenberger (1976);

$$
\widehat{\beta}_{i m t}=\frac{\sum_{s=1, s \neq t}^{T}\left(R_{i s}-\bar{R}_{i}\right)\left(R_{m s}-\bar{R}_{m}\right)}{\sum_{s=1}^{T}\left(R_{m s}-\bar{R}_{m}\right)^{2}}
$$




$$
\begin{aligned}
& \widehat{\gamma}_{i m t}=\frac{\sum_{s=1, s \neq t}^{T}\left(R_{i s}-\bar{R}_{i}\right)\left(R_{m s}-\bar{R}_{m}\right)^{2}}{\sum_{s=1}^{T}\left(R_{m s}-\bar{R}_{m}\right)^{3}} \\
& \widehat{\theta}_{i m t}=\frac{\sum_{s=1, s \neq t}^{T}\left(R_{i s}-\bar{R}_{i}\right)\left(R_{m s}-\bar{R}_{m}\right)^{3}}{\sum_{s=1}^{T}\left(R_{m s}-\bar{R}_{m}\right)^{4}}
\end{aligned}
$$

The marginal rates of substitution are calculated using the GMM method. The orthogonality conditions are derived as follows. We obtain the following relationships from the SW four-moment CAPM in equation (13); $k_{1}=\frac{b_{2} \sigma\left(r_{m}\right)}{b_{1} \gamma\left(r_{m}\right)}$ and $k_{2}=\frac{b_{3} \sigma\left(r_{m}\right)}{b_{1} \theta\left(r_{m}\right)}$. These relationships can also be represented as $b_{2}=\frac{k_{1} b_{1} \gamma\left(r_{m}\right)}{\sigma\left(r_{m}\right)}$ and $b_{3}=\frac{k_{2} b_{1} \theta\left(r_{m}\right)}{\sigma\left(r_{m}\right)}$. Replacing $b_{2}$ and $b_{3}$ with these relationships, the SW four-moment CAPM can be rewritten as

$$
E\left(r_{i}\right)-r_{f}=\left(b_{1} \beta_{i m}+\frac{k_{1} b_{1} \gamma\left(r_{m}\right)}{\sigma\left(r_{m}\right)} \gamma_{i m}+\frac{k_{2} b_{1} \theta\left(r_{m}\right)}{\sigma\left(r_{m}\right)} \theta_{i m}\right)\left(E\left(r_{m}\right)-r_{f}\right)
$$

and therefore, our orthogonality condition, $h_{t}(\mathbf{\Theta})$, for the estimation of $k_{1}$ and $k_{2}$ is

$$
E\left[R_{i t}-b_{0}-b_{1}\left\{\widehat{\beta}_{i m t}+\widehat{\gamma}\left(R_{m}\right) \widehat{\gamma}_{i m t} \widehat{\sigma}\left(R_{m}\right)^{-1} k_{1}+\widehat{\theta}\left(R_{m}\right) \widehat{\theta}_{i m t} \widehat{\sigma}\left(R_{m}\right)^{-1} k_{2}\right\} R_{m t}\right]=0
$$

where $R_{i t}$ and $R_{m t}$ are deflated excess returns of portfolio $i$ and the market portfolio at time $t, \widehat{\sigma}\left(R_{m}\right), \widehat{\gamma}\left(R_{m}\right), \widehat{\theta}\left(R_{m}\right), \widehat{\beta}_{i m t}, \widehat{\gamma}_{i m t}$, and $\widehat{\theta}_{i m t}$ are sample estimates, and $\Theta^{\prime}=\left(\alpha_{0}, \alpha_{1}, k_{1}\right.$, $\left.k_{2}\right)$ is a vector of parameters to be estimated. Therefore, for the estimation of $k_{1}$ and $k_{2}$, we have 4 parameters to estimate and $N^{3}$ orthogonal conditions $\left(N^{3}-4\right.$ degrees of freedom). On the other hand for the estimation of $k_{1}$, we have three parameters, $\boldsymbol{\Theta}^{\prime}=\left(\alpha_{0}, \alpha_{1}, k_{1}\right)$, and $N^{2}$ orthogonal conditions ( $N^{2}-3$ degrees of freedom). The parameters are estimated until convergence by iterating on the weighting matrix.

In this study, for the estimation of $k_{1}, N$ is set to 5 and 25 risky asset portfolios are formed. For the estimation of $k_{1}$ and $k_{2}, N$ is set to 3 and 27 portfolios are constructed. This should give us sensible estimates of the marginal rates of substitution, results are reported in table 3.

Panel A of table 3 reports the estimates of the market's marginal rate of substitution between skewness and risk, $\widehat{k}_{1}$, for the SW three-moment CAPM. The model is not rejected 
both when the market crash of October 1987 is included and when the market crash of October 1987 is excluded. Note that negative $k_{1}$ is expected. This implies that the representative investor likes positive skewness. We have negative $k_{1}(-0.1266)$ when the market crash of October 1987 is included but positive $k_{1}(0.1693)$ when the market crash of October 1987 is excluded. However, these estimates are not significantly different from zero and we do not find evidence of a significant relation between risk and skewness. Lim (1989) and Sears and Wei (1988) find significant negative relationship between skewness and risk when the SW three-moment CAPM is not rejected. However, their results are sensitive to the sample period used.

Panel B of table 3 reports the estimates of $k_{1}$ and $k_{2}$ for the SW four-moment CAPM in equation (13). Note that in this four-moment CAPM, $\widehat{k}_{1}$ has the correct sign (negative) both when the market crash of October 1987 is included (-3.7964) and when the market crash of October 1987 is excluded (-0.3047). However, none of them are significantly different from zero. On the other hand, although we expect positive $\widehat{k}_{2}$ (the representative investor is averse to kurtosis), the estimates when the market crash of October 1987 is included and when the market crash of October 1987 is excluded are negative (-2.7887 and -1.6856 , respectively). Again all estimates are not significantly different from zero, suggesting that the expected relationship between skewness and risk is not strong.

We do not find positive evidence on a relationship between risk and skewness or kurtosis for US investors for the given sample period. We believe that it is difficult to find significant estimates of $k_{1}$ and $k_{2}$ in mature markets, since the returns in these markets are close to normal and do not have significantly large skewness or kurtosis. In our example, this argument is supported by the fact that the estimates of the normalised skewness and normalised excess kurtosis of the S\&P 500 index return in table 3 are not significantly different from zero when the 1987 market crash is excluded. When the 1987 market crash is 
included, we have significant estimates both for normalised skewness and normalised excess kurtosis. However, the 1987 market crash, one observation, does not seem enough to give us significant estimates of $k_{1}$ and $k_{2}$.

Another reason why we fail to have significant estimates of $k_{1}$ and $k_{2}$ may be the timevarying properties of risks. The studies of Friend and Westerfield (1980), Lim (1989), and Sears and Wei (1988) suggest that estimates of $k_{1}$ change in different sample periods. Timevarying systematic risks may be an appropriate tool for the analysis. In addition, estimates of higher moments are more sensitive to a small number of extreme returns. In this case, although we construct portfolios in an appropriate way to reduce measurement errors, ex post returns may have quite different properties from ex ante returns especially in higher moments.

\subsection{Estimation Procedure of Higher Moment CAPM}

The four-moment CAPM is tested using Hansen's (1982) generalized method of moments (GMM); this procedure is distribution free and is used when the assumption of normality is not appropriate. The evidence presented in panel $\mathrm{B}$ of table 2 strongly suggests that it would be inappropriate to assume normality for emerging market returns. We explain the GMM estimation for the SW four-moment CAPM of equation (13). Detailed explanations for the other models follow later. Note that all the other models use the same procedure differing only in the orthogonality conditions imposed.

Following the three-moment CAPM of Lim (1989), the orthogonality conditions, $h_{t}(\mathbf{\Theta})$, for estimating the SW four-moment CAPM are

$$
\begin{aligned}
& E\left[\begin{array}{c}
\left\{\sigma\left(R_{m}\right)+k_{1} \gamma\left(R_{m}\right)+k_{2} \theta\left(R_{m}\right)\right\} R_{i t} \\
-\left\{\sigma\left(R_{m}\right) \beta_{i m}+k_{1} \gamma\left(R_{m}\right) \gamma_{i m}+k_{2} \theta\left(R_{m}\right) \theta_{i m}\right\} R_{m t}
\end{array}\right]=0 \\
& E\left[R_{i t} R_{m t}-\mu\left(R_{m}\right) R_{i t}-\beta_{i m}\left\{R_{m t}-\mu\left(R_{m}\right)\right\}^{2}\right]=0
\end{aligned}
$$




$$
\begin{aligned}
& E\left[\begin{array}{c}
R_{i t} R_{m t}^{2}-2 \mu\left(R_{m}\right) R_{i t} R_{m t}+\mu\left(R_{m}\right)^{2} R_{i t}-\sigma\left(R_{m}\right)^{2} R_{i t} \\
-\gamma_{i m}\left\{R_{m t}-\mu\left(R_{m}\right)\right\}^{3}
\end{array}\right]=0 \\
& E\left[\begin{array}{c}
R_{i t} R_{m t}^{3}-3 \mu\left(R_{m}\right) R_{i t} R_{m t}^{3}+3 \mu\left(R_{m}\right)^{2} R_{i t} R_{m t} \\
-\mu\left(R_{m}\right)^{3} R_{i t}-\gamma\left(R_{m}\right)^{3} R_{i t}-\theta_{i m}\left\{R_{m t}-\mu\left(R_{m}\right)\right\}^{4}
\end{array}\right]=0 \\
& E\left[R_{m t}-\mu\left(R_{m}\right)\right]=0 \\
& E\left[\left\{R_{m t}-\mu\left(R_{m}\right)\right\}^{2}-\sigma\left(R_{m}\right)^{2}\right]=0 \\
& E\left[\left\{R_{m t}-\mu\left(R_{m}\right)\right\}^{3}-\gamma\left(R_{m}\right)^{3}\right]=0 \\
& E\left[\left\{R_{m t}-\mu\left(R_{m}\right)\right\}^{4}-\theta\left(R_{m}\right)^{4}\right]=0
\end{aligned}
$$

where $i=1, \ldots, N$ and $N$ is the number of emerging markets. The first $N$ orthogonality conditions come from the four-moment CAPM of equation (13). The next $3 N$ orthogonality conditions are $N$ conditions for beta, $N$ conditions for co-skewness, and $N$ conditions for co-kurtosis. The last four orthogonality conditions are for mean, variance, skewness, and kurtosis of the market returns. Therefore, we have $4 N+4$ orthogonality conditions and $3 N+6$ parameters, $\boldsymbol{\Theta} \equiv\left(\beta_{1 m}, \beta_{2 m}, \ldots, \beta_{N m}, \gamma_{1 m}, \gamma_{2 m}, \ldots, \gamma_{N m}, \theta_{1 m}, \theta_{2 m}, \ldots, \theta_{N m}, \mu\left(R_{m}\right), \sigma\left(R_{m}\right)\right.$, $\left.\gamma\left(R_{m}\right), \theta\left(R_{m}\right), k_{1}, k_{2}\right)^{\prime}$, to be estimated. There are $N-2$ overidentifying restrictions in the system. The numbers of the overidentifying restrictions for the other models are explained later.

Without losing asymptotic efficiency, we apply a linear Taylor series approximation about our sample estimators to deal with the nonlinearity of the orthogonality conditions. ${ }^{3}$ For the one-step Gauss-Newton procedure, the GMM estimate, $\widehat{\boldsymbol{\Theta}}_{T}$, is the value of $\boldsymbol{\Theta}$ that minimizes

$$
\left[g_{T}(\boldsymbol{\Theta})\right]^{\prime} \overline{\mathbf{S}}_{T}^{-1}\left[g_{T}(\boldsymbol{\Theta})\right]
$$

where

$$
g_{T}(\boldsymbol{\Theta}) \equiv T^{-1} \sum_{t=1}^{T} h_{t}(\boldsymbol{\Theta})
$$


and

$$
\overline{\mathbf{S}}_{T} \equiv T^{-1} \sum_{t=1}^{T}\left[h_{t}(\overline{\boldsymbol{\Theta}})\right]\left[h_{t}(\overline{\mathbf{\Theta}})\right]^{\prime}
$$

and sample estimators of the parameter vector, $\overline{\boldsymbol{\Theta}}$, are calculated from the definition of each parameter.

The GMM estimate can be treated as if

$$
\widehat{\boldsymbol{\Theta}}_{T} \approx N\left(\boldsymbol{\Theta}_{0},\left(T \widehat{\mathbf{D}}_{T} \overline{\mathbf{S}}_{T}^{-1} \widehat{\mathbf{D}}_{T}^{\prime}\right)^{-1}\right)
$$

where

$$
\widehat{\mathbf{D}}_{T}=\left.\frac{\partial g_{T}(\boldsymbol{\Theta})}{\partial \boldsymbol{\Theta}^{\prime}}\right|_{\Theta=\widehat{\Theta}_{T}}
$$

The Lagrange Multiplier (LM) test statistic for the validity of the restricted four-moment CAPM is

$$
T\left[g_{T}(\widehat{\boldsymbol{\Theta}})\right]^{\prime} \overline{\mathbf{S}}_{T}^{-1}\left[g_{T}(\widehat{\boldsymbol{\Theta}})\right] \rightarrow \chi^{2}(N-2)
$$

since we have $N-2$ degrees of freedom. Note that this test statistic is equivalent to that of the overidentifying restrictions, see Hansen (1982).

There is a statistical problem in estimating higher-moment CAPMs; the systematic risk measures, $\beta_{i m}, \gamma_{i m}$, and $\theta_{i m}$, are collinear. The correlation matrix obtained from sample estimators, $\bar{\beta}_{i m}, \bar{\gamma}_{i m}$, and $\bar{\theta}_{i m}$ is reported in table 4 . It is apparent that the data are quite collinear which may well lead to identification problems.

A referee has commented that when all 17 emerging markets are considered jointly, the GMM system becomes too large. For example, for our SW four moment CAPM, we have $72(17 \times 4+4)$ orthogonality conditions. In this case, the estimation results may become unreliable, see Ferson and Foerster (1994) and Bekaert and Uris (1996) for further discussion on this point. The referee also suggests grouping emerging markets sensibly to avoid collinearity problem in the GMM system. 
Accordingly we have divided our emerging markets into groups to reduce the orthogonality conditions and possible multicollinearity. In previous work Hwang and Satchell (1998) analyse both currency and equity return in emerging markets, and suggest that there are different regional factors in emerging markets. They find that emerging markets factors can be related to Asia, Southern Asia, Latin America, Central America, and Middle East groupings. In this study, we divide the 17 emerging markets into three groups and estimate a GMM system for each of the three groups. The three groups are the Asian group which includes India, Korea, Thailand, Taiwan, Malaysia, Pakistan, and Philippines (7 countries), the Latin American Group which includes Argentina, Brazil, Chile, Mexico, Colombia, and Venezuela (6 countries), and the Other Country group which includes Greece, Zimbabwe, Jordan, and Nigeria (4 countries). This reduces the number of orthogonality conditions to $32(7 \times 4+4)$ for the Asian group with the SW four moment CAPM and less for the other two groups.

\subsubsection{Mean-variance CAPM (Model I)}

Table 5 reports the results of the GMM estimates of the mean-variance CAPM for the emerging markets. That is,

$$
E\left(R_{i}\right)=\alpha_{1} \beta_{i m}
$$

where $\alpha_{1}=E\left(R_{m}\right)$. For the mean-variance CAPM, the orthogonality conditions consist of equations (37), (26), and (29) and the number of the overidentifying restrictions is $N$.

Table 5 shows that the LM statistics do not reject the mean-variance CAPM except for the Latin American group. Note that Asian markets are relatively well explained with the traditional mean-variance CAPM. The value of the adjusted $R^{2}$ is relatively high. India and Pakistan are not explained by the mean-variance CAPM. The results are consistent with Hwang and Satchell (1998) who show that Eastern Asia has different factors from those of 
Southern Asia such as India, Pakistan, and Sri Lankan.

On the other hand, the mean-variance CAPM is rejected for the Latin American markets both when the market crash of October 1987 is included and when the market crash of October 1987 is excluded. Only Mexico which has a strong relation with the US is explained by the mean-variance CAPM. Also note that Greece has a significant beta. Greece is often considered one of the European markets which has a significant contribution to the world index. The values of the adjusted $R^{2}$ are small for the Latin America and Other Country groups, suggesting that the mean-variance CAPM is not an appropriate model for these markets.

The results in table 5 suggest that the mean-variance CAPM can be used for Eastern Asian countries and countries which have a close relationship with mature markets. One of the main reasons why the Latin American markets are not explained with the mean-variance CAPM may be the highly volatile Latin American currency returns, see Hwang and Satchell (1998).

\subsubsection{KL Three-moment CAPM (Model II)}

Table 6 shows the results of the GMM estimates for the following KL three-moment CAPM;

$$
E\left(R_{i}\right)=\alpha_{1} \beta_{i m}+\alpha_{2} \gamma_{i m}
$$

The orthogonality conditions are equations (38), (26), (27), (29), (30), and (31). For the

KL three-moment CAPM, the number of the overidentifying restrictions is $N-2$.

Here, we do not reject the model for the Asian and Other Country groups, but reject the model for the Latin American group at the 1\% level as we did in the mean-variance CAPM. Although the coefficients, $\alpha_{1}$ and $\alpha_{2}$, are not significant as in Friend and Westfield (1980), Lim (1989), and Sears and Wei (1988), the market price of beta, $\alpha_{1}$, and the market price of co-skewness, $\alpha_{2}$, have correct signs when the 1987 crash is excluded; $\alpha_{1}$ and $\alpha_{2}$ are 
positive, since $\gamma\left(r_{m}\right)<0$. Investors need more return for the negative skewness of the market portfolio over the test period and thus, expected returns should increase to the co-skewness. These results do not apply with the case when the 1987 crash is included, since Asian and Other Country groups have negative $\alpha_{2}$. However, the coefficients are insignificant.

Another interesting point is that none of the estimates of $\gamma_{i m}$ is significant when the 1987 crash is excluded, while we can find significant $\widehat{\gamma}_{i m}$ in the Latin American group when the 1987 crash is included. In particular, the adjusted $R^{2}$ increases dramatically for the Latin America and other countries groups, especially when the 1987 crash is included. Here, the adjusted $R^{2}$ for these two groups are now larger than that of Asia. For the Asian countries the adjusted $R^{2}$ is not increased with the inclusion of co-skewness and none of the co-skewness estimates are significant in the presence of the 1987 market crash. This suggests that for these countries co-skewness may not be an appropriate risk measure. It is by no means clear, however, that it is correct to regard the 1987 crash as a one-off bizarre event to be ignored or downscaled.

The addition of co-skewness as a risk measure increases explanatory power of the KL three-moment CAPM for some emerging markets. Our results suggest that Latin America and Other Country groups can be explained better with co-skewness.

\subsubsection{SW Three-moment CAPM (Model V)}

Table 7 shows the results of the GMM estimates for the SW three-moment CAPM;

$$
E\left(R_{i}\right)=\left[\frac{\sigma\left(R_{m}\right) \beta_{i m}}{\sigma\left(R_{m}\right)+k_{1} \gamma\left(R_{m}\right)}+\frac{k_{1} \gamma\left(R_{m}\right) \gamma_{i m}}{\sigma\left(R_{m}\right)+k_{1} \gamma\left(R_{m}\right)}\right] E\left(R_{m}\right)
$$

In this case, the orthogonality conditions consist of equations (39), (26), (27), (29), (30), and (31), and the number of the overidentifying restrictions is $N$. This differs from the KL model by using the restrictions of the marginal rate of substitution between skewness and risk $\left(k_{1}\right)$. 
As explained above, the marginal rates of substitution reported in table 3 are used for the estimation of the SW three-moment CAPM model in the emerging markets. This is known as a sequential GMM technique.. That is, consistent estimates $\widehat{k}_{1}$ of $k_{1}$ will be used as given values for the estimation of the SW three-moment CAPM. The sampling errors in the estimation of $k_{1}$ should be considered when other parameters in the SW three-moment CAPM are estimated for the fixed $\widehat{k}_{1}$, see Bekaert (1994), Burnside (1994), and Heaton (1995) for further details. We use Newey and West (1987) method to construct a consistent estimate of the variance-covariance matrix as in Bekaert (1994). In addition, we use a multistep Gauss-Newton procedure: using the previous estimators of $\mathbf{S}_{T}$ and $\boldsymbol{\Theta}_{T}$, the calculation was repeated until there is no change in the estimates of $\boldsymbol{\Theta}_{T}$.

Table 7 reports the results of the multi-step Gauss-Newton procedure. The LM statistics show that we reject the SW three-moment CAPM at 1\% level for Latin America and Asia (four out of six cases). As in the KL three-moment CAPM, none of the estimates of $\gamma_{i m}$ except some Latin American countries is significant. We do not calculate adjusted $R^{2}$ values for the SW three-moment CAPM, since the SW three-moment CAPM is nonlinear model.

The SW three-moment CAPM does not seem to explain emerging markets well. The LM statistics of SW three-moment CAPM are much larger than those of the KL three-moment CAPM. In addition, the number of significant beta and co-skewness in the SW three-moment CAPM is smaller than that in the KL three-moment CAPM.

Although the SW three-moment CAPM allows us to divide coefficients of the KL threemoment CAPM into the market risk premium and the marginal rates of substitution, the results in table 7 do not seem to be encouraging. The KL higher-moment CAPMs are an ex ante model as is the conventional mean-variance CAPM and thus, theoretically we do not expect a negative market premium. In addition, the actual average value of our deflated excess market returns used in this study (deflated excess MSCI world index total returns) 
is always positive. These theoretical and empirical explanation suggest that we may not get a great deal of insight from the SW higher-moment CAPM. Moreover, as explained above, we have some difficulties in estimating the marginal substitution rates.

We tried to estimate the SW four-moment CAPM as described by equations (25) to (32). However, this failed to converge.

\subsubsection{KL Four-moment CAPM (Model III)}

In table 8 we represent the results of the GMM estimates for the KL four-moment CAPM given by equation (11). Here, the orthogonality conditions consist of equations (11), (26), (27), (28), (29), (30), (31), and (32), and the number of the overidentifying restrictions is $N-3$. The sample estimators of $\alpha_{1}, \alpha_{2}$, and $\alpha_{3}$ are obtained from the GMM estimation described in subsection 2.2. The LM statistics in table 8 shows that we do not reject the model at the 5\% level except Latin America when the 1987 market crash is excluded. The adjusted $R^{2}$ values are larger than those in tables 6 and 5 . The LM statistics and $R^{2}$ indicate that the KL four-moment CAPM explains emerging markets better than other models we reported in the previous subsections.

As explained in section 1 , we expect $\alpha_{1}>0, \alpha_{2}>0$, and $\alpha_{3}>0$, since $\widehat{\gamma}\left(r_{m}\right)<0$. None of the coefficients are significant except $\alpha_{1}$ and $\alpha_{3}$ of Latin American group in the presence of the market crash.

When we compare the results to those of the KL three-moment CAPM in table 6 , the numbers of significant co-kurtosis terms are 9 when the market crash is included and also 9 when the market crash is excluded, respectively, without changes in the significance of the estimated $\beta_{i m}$. Interestingly, the significance of co-skewness in Latin America for the KL three-moment CAPM disappears and none of the co-skewness estimates in the KL fourmoment CAPM is significant. This suggests that Latin American countries can be better 
explained with co-kurtosis than co-skewness when the 1987 market crash is included.

The adjusted $R^{2}$ values of the four-moment CAPM are all higher than those of the KL three-moment CAPM. In particular, Latin American and Asian groups when the 1987 market crash is included and Asian and Other Country groups when the 1987 market crash is excluded show significant benefits from the inclusion of the co-kurtosis. However, the Other Country group in the presence of the market crash and the Latin American group when the 1987 market crash is excluded do not have larger adjusted $R^{2}$ by adding co-kurtosis, see the adjusted $R^{2}$ in tables 5 and 6 .

\subsubsection{KL Second- and Fourth-moment CAPM (Model IV)}

The different explanatory power of systematic risks in tables 5,6 , and 8 is further investigated by estimating the mean-variance CAPM with co-kurtosis. In table 9 we report the estimation results of the model. The CAPM with co-kurtosis is represented as

$$
E\left(R_{i}\right)=\alpha_{1} \beta_{i m}+\alpha_{3} \theta_{i m}
$$

When the skewness of the market portfolio is negligible, that is, $\gamma\left(r_{m}\right) \approx 0$, the second term of the right hand side of equation (11) may be disregarded $\left(\alpha_{2}=\frac{d E(w)}{d \gamma(w)} \gamma\left(r_{m}\right) \approx 0\right)$. The orthogonality conditions for the CAPM with kurtosis are equations (40), (26), (28), (29), (30), (31), and (32) and the number of overidentifying restrictions is $N-2$.

As in table 8, the signs on the coefficients $\left(\alpha_{1}\right.$ and $\left.\alpha_{3}\right)$ are not always positive and the estimates are not significant. The LM statistics show that we reject only one case, the Latin American group when the 1987 market crash is excluded. This is the same as the KL four-moment CAPM. However, the number of significant beta and co-kurtosis terms is larger than those of the KL four-moment and three-moment CAPMs.

The adjusted $R^{2}$ values in table 9 together with those in tables 5,6 , and 8 suggest the following; when the 1987 market crash is included, the Latin American group is explained with 
beta and co-kurtosis, the Asian group is explained by beta, co-skewness, and co-kurtosis, and the Other Country group is explained by beta and co-skewness or beta and co-kurtosis. On the other hand when the 1987 market crash is excluded, the Latin American group is explained with beta and co-skewness, and the Asian and the Other Country groups are explained by beta, co-skewness, and co-kurtosis.

The KL second- and fourth-moment CAPM does not seem to be inferior to the Kraus and Litzenberger three-moment CAPM for emerging markets. The number of significant risks and the LM statistics support the KL second- and fourth-moment CAPM rather than the KL three-moment CAPM. The individual emerging markets may be better explained with co-kurtosis rather than co-skewness. Concluding from table 9, co-kurtosis rather than co-skewness may be a more appropriate additional risk measure for the emerging markets.

\subsection{Summary of GMM Results}

The adjusted $R^{2}$, LM statistics, and number of significant systematic risks support the modelling of higher moments for emerging markets. Our ancillary assumptions about the $\alpha_{i} \mathrm{~S}$ and $k_{i} \mathrm{~S}$ and their signs are not contradictory to the empirical findings.

Attempts to utilize log-utility, which obviates the need to estimate $k_{1}$ and $k_{2} \operatorname{did}$ not do any better, indeed our iterations failed to converge. This is the reason why we do not report results for the SW four-moment CAPM with log-utility. Another assumption, that of a simple representative agent, seems too strong as well. It may be better to consider a multiple-agent equilibrium so that risk premia are generated by more than two funds. However, pricing assets in this situation tends to be much more complicated.

Turning to the role of the market crash, all estimations were re-calculated without October 1987. The effect of this was actually minimal except that co-skewness was dramatically increased without the crash. This seemingly paradoxical result follows from the fact that 
the numerator of co-skewness did not change much with the exclusion of the crash whilst the denominator was substantially reduced.

\section{HIGHER-MOMENT DGP}

The previous sections avoid a specification of the DGP and use the GMM to estimate the higher-moment CAPMs. However, as mentioned earlier, the estimated versions of the higher-moment CAPMs have a statistical problem, non-identifiability between risk measures. Barone-Adesi (1985) suggests the quadratic market model can be used to reduce the collinearity problem in the KL three-moment CAPM.

In this section, we specify the DGPs; the linear market model, the quadratic market model, and the cubic market model. The DGPs are shown to be consistent with their equivalent higher-moment CAPMs as well as reducing the multicollinearity of the systematic risk measures.

We first consider the linear market model. That is, the DGP of an asset $i$ is presented as a linear function of the excess rate of return on the market portfolio,

$$
r_{i, t}-r_{f}=\alpha_{0, i}+\alpha_{1, i}\left(r_{m, t}-r_{f}\right)+\varepsilon_{i, t}
$$

Subtracting the expected value of equation (41) from equation (41), and using the definition of the systematic risk measures, $\beta_{i m}, \gamma_{i m}$, and $\theta_{i m}$, in equation (2), (3), and (4), we obtain $\beta_{i m}=\gamma_{i m}=\theta_{i m}=\alpha_{1, i}$. That is, when individual asset's excess rate of return is simply represented as a linear function of excess rate of return on the market portfolio, the mean-variance CAPM rather than higher-moment CAPMs should be used. Otherwise, the systematic risk measures in the higher-moment CAPMs are perfectly collinear.

For the following quadratic market model,

$$
r_{i, t}-r_{f}=\alpha_{0, i}+\alpha_{1, i}\left(r_{m, t}-r_{f}\right)+\alpha_{2, i}\left(r_{m, t}-E\left(r_{m}\right)\right)^{2}+\varepsilon_{i, t}
$$


using the same method as in the linear market model, we obtain

$$
\begin{aligned}
\beta_{i m} & =\alpha_{1, i}+\alpha_{2, i} \frac{\gamma\left(r_{m}\right)^{3}}{\sigma\left(r_{m}\right)^{2}} \\
\gamma_{i m} & =\alpha_{1, i}+\alpha_{2, i} \frac{\theta\left(r_{m}\right)^{4}-\sigma\left(r_{m}\right)^{4}}{\gamma\left(r_{m}\right)^{3}}
\end{aligned}
$$

We suggest only beta and co-skewness, since for the two parameters, $\alpha_{1, i}$ and $\alpha_{2, i}$, of the quadratic market model, only the first two systematic risk measures can be derived, unless other information on the relation between co-kurtosis and beta and co-skewness is available; KL and Giovanni (1985) provide further discussion on the quadratic market model. The equations (43) and (44) give us some insight into the nature of the multicollinearity between $\beta_{i m}$ and $\gamma_{i m}$. For example, if the weights on $\alpha_{2, i}$ in equations (43) and (44) are equal, $\beta_{i m}=\gamma_{i m}$. If either $\alpha_{1, i}$ or $\alpha_{2, i}$ is constant for all $i$, then $\beta_{i m}$ and $\gamma_{i m}$ will be collinear.

A generalization of equation (42) is the cubic market model given below

$$
r_{i, t}-r_{f}=\alpha_{0, i}+\alpha_{1, i}\left(r_{m, t}-r_{f}\right)+\alpha_{2, i}\left(r_{m, t}-E\left(r_{m}\right)\right)^{2}+\alpha_{3, i}\left(r_{m, t}-E\left(r_{m}\right)\right)^{3}+\varepsilon_{i, t}(45
$$

We can use equation (45) to evaluate the relationships given in equation (11). We present this as a theorem.

Theorem 3 If we assume the validity of the KL four-moment CAPM as given by (11) and a DGP as in (45), then the systematic risk measures, $\beta_{i m}, \gamma_{i m}$, and $\theta_{i m}$, are

$$
\begin{array}{r}
\beta_{i m}=\alpha_{1, i}+\frac{\alpha_{2, i} \gamma\left(r_{m}\right)^{3}+\alpha_{3, i} \theta\left(r_{m}\right)^{4}}{\sigma\left(r_{m}\right)^{2}} \\
\gamma_{i m}=\alpha_{1, i}+\frac{\alpha_{2, i}\left\{\theta\left(r_{m}\right)^{4}-\sigma\left(r_{m}\right)^{4}\right\}+\alpha_{3, i}\left\{\phi\left(r_{m}\right)^{5}-\gamma\left(r_{m}\right)^{3} \sigma\left(r_{m}\right)^{2}\right\}}{\gamma\left(r_{m}\right)^{3}} \\
\theta_{i m}=\alpha_{1, i}+\frac{\alpha_{2, i}\left\{\phi\left(r_{m}\right)^{5}-\sigma\left(r_{m}\right)^{2} \gamma\left(r_{m}\right)^{3}\right\}+\alpha_{3, i}\left\{\varphi\left(r_{m}\right)^{6}-\gamma\left(r_{m}\right)^{6}\right\}}{\theta\left(r_{m}\right)^{4}}
\end{array}
$$

where $\phi\left(r_{m}\right)=E\left[\left\{r_{m}-E\left(r_{m}\right)\right\}^{5}\right]^{1 / 5}, \varphi\left(r_{m}\right)=E\left[\left\{r_{m}-E\left(r_{m}\right)\right\}^{6}\right]^{1 / 6}$, and the other parameters are defined the same as in the previous sections.

Proof. See the explanation of the above linear market model. We omit details. 
The higher-moment CAPMs depend on the highest moment of the DGP; if the DGP is quadratic, we cannot use the four-moment CAPM but the three-moment CAPM. Only when the DGP is cubic, can we use the four-moment CAPM. Therefore, if the unknown DGP is a quadratic and the four-moment CAPM is estimated, the four-moment CAPM is not identifiable, and the multicollinearity problem in the systematic risk measures creates estimation problems.

Tables 10 and 11 report the GLS estimates for the quadratic and cubic market models. Here we do not divide the 17 emerging markets into groups, since the problems that arise in a large system in GMM estimation is not expected in the GLS estimation that we carry out. Table 10 shows that the significant estimates of $\alpha_{1, i}$ are all positive and the significant estimates of $\alpha_{2, i}$ are all negative except one. This implies that individual emerging market returns increase (decrease) as the market portfolio increases (decreases), but decrease as the world market returns become more volatile. In addition, table 11 reports that the significant estimates of $\alpha_{3, i}$ are all positive except one. This has the implication that the emerging market returns increase (decrease) as the positive (negative) skewness of the market portfolio becomes larger. However, the total number of significant estimates in the cubic market model is less than that in the quadratic market model. The $R^{2}$ values also suggest that there is not much gain from using the cubic market model.

The $R^{2}$ values are relatively small, when they are compared with other $R^{2}$ values in the previous tables. The difference comes from the fact that the $R^{2}$ values in tables 5 to 9 are obtained from the cross-sectional calculation, while the $R^{2}$ values in tables 10 and 11 are obtained from the seemingly unrelated regressions model. The beta, co-skewness, and co-kurtosis calculated from the GLS estimates of the DGP parameters (see the relationship between systematic risk measures and $\alpha_{1, i}, \alpha_{2, i}$, and $\alpha_{3, i}$ ) are not significantly different from the sample estimators, $\bar{\beta}_{i m}, \bar{\gamma}_{i m}$, and $\bar{\theta}_{i m}$. 


\section{CONCLUSION}

This study proposes the four-moment CAPM that explicitly involves skewness and kurtosis as additional risk measures. We use a multivariate approach and estimate the models with GMM. like studies for mature markets such as Friend and Westerfield (1980), Sears and Wei (1988), Homaifar and Graddy (1988), and Lim (1989), our study shows that there is no significant relationship between expected return and risk $\left(\alpha_{1}\right)$, skewness $\left(\alpha_{2}\right)$, and kurtosis $\left(\alpha_{3}\right)$. However, we also find insignificant marginal rates of substitution between risk and skewness $\left(k_{1}\right)$ and kurtosis $\left(k_{2}\right)$. This is due to the lack of normalised skewness and normalised kurtosis in US returns.

Despite the poor estimates of the coefficients and marginal rates of substitution, however, higher moment CAPMs seem to be preferred to the conventional mean-variance CAPM. Some test statistics such as the adjusted $R^{2}$ and the LM statistics reported in this study suggest that emerging markets are better explained with higher-moments CAPMs. Interestingly, co-kurtosis has at least as much explanatory power as co-skewness. This is consistent with the result in table 2 that the main source of nonnormality in emerging markets is kurtosis rather than skewness.

Our initial approach explicitly imposes the condition that the market is efficient, $\beta_{m m}=$ $\gamma_{m m}=\theta_{m m}=1$ as in Sears and Wei $(1985,1988)$ and $\operatorname{Lim}(1989)$. When we use an alternative approach using DGPs, we can condition on the market, as in Sharpe's market model. In addition, the high multicollinearity in sample co-moments seems to make it hard to jointly estimate co-skewness and co-kurtosis. Therefore, we specified higher-moment DGPs such as the quadratic market model as in Kraus and Litzenberger (1976) and Barone-Adesi (1985). We showed that higher-moment DGPs are consistent with higher-moment CAPMs, while reducing the collinearity in the parameters.

Adding a note of realism to our study, we acknowledge that we are applying a station- 
ary analysis to an evolutionary problem. Our reason for doing so is to assess the degree of explanation possible using higher moment CAPMs with emerging markets data. Our predictable conclusion is that whilst the use of higher moments seems to improve matters, it cannot compensate for the fundamental non-stationarity of emerging market returns. The non-normality of emerging market returns is not enough in itself to build models that fail to take account of the evolutionary nature of emerging markets. Nevertheless, we do not regard the construction of these models as having no practical relevance. In Hwang and Satchell (1998) we have used models similar to the ones in this paper to assess risk adjusted performance of emerging market funds. We found there that outperformance in emerging markets is eliminated once risk adjustment for higher moments is carried out.

\section{END NOTES}

1. Scott and Horvath (1980) use the extra condition called strict consistency in preference direction, see A3, p916, Scott and Horvath, 1980. This is a strong condition. More generally, Kraus and Litzenberger (1983) show that in a Pareto efficient allocation, the fourth derivative of the aggregated utility function of the representative agent does not exhibit a negative or positive sign, even if all the individuals have utility functions that have fourth derivatives with the same sign.

2. Strict consistency in preference will imply that $\frac{\partial E[U(w)]}{\partial \gamma(w)}>0$, see Scott and Horvath, 1980, theorem 1. For the approximation given by (14), we only require that $U^{\prime \prime \prime}(E(w))>0$. 3. The estimators obtained using this method are asymptotically the same as the unmodified estimators, see $\operatorname{Lim}(1989)$. 


\section{APPENDIX}

\section{Appendix 1}

Since the initial investment is set to 1 , the moments of end of period wealth are equivalent to those of the rate of return on the portfolio. That is, $\sigma(w)=\sigma\left(r_{p}\right), \gamma(w)=\gamma\left(r_{p}\right)$ and $\theta(w)=\theta\left(r_{p}\right)$. The equation, $\sum_{i=1}^{N} x_{i} \beta_{i p}=1$, can be shown as

$$
\begin{aligned}
\sum_{i=1}^{N} x_{i} \beta_{i p} & =\sum_{i=1}^{N} x_{i} \frac{E\left[\left\{r_{i}-E\left(r_{i}\right)\right\}\left\{r_{p}-E\left(r_{p}\right)\right\}\right]}{E\left[\left\{r_{p}-E\left(r_{p}\right)\right\}^{2}\right]} \\
& =\frac{E\left[\left\{\sum_{i=1}^{N} x_{i} r_{i}-\sum_{i=1}^{N} x_{i} E\left(r_{i}\right)\right\}\left\{r_{p}-E\left(r_{p}\right)\right\}\right]}{E\left[\left\{r_{p}-E\left(r_{p}\right)\right\}^{2}\right]} \\
& =1
\end{aligned}
$$

using $\sum_{i=1}^{N} x_{i} r_{i}=r_{p}-x_{0} r_{f}$ and $\sum_{i=1}^{N} x_{i} E\left(r_{i}\right)=E\left(r_{p}\right)-x_{0} r_{f}$. Therefore, $\sigma(w)=\sum_{i=1}^{N} x_{i} \beta_{i p} \sigma\left(r_{p}\right)$.

With the same method, $\sum_{i=1}^{N} x_{i} \gamma_{i p}=1$ and $\sum_{i=1}^{N} x_{i} \theta_{i p}=1$ can be easily shown and the results follow.

\section{Appendix 2}

A Lagrangian for the given maximization problem is

$$
L=E[U(w)]-\lambda\left(x_{0}+\sum_{i=1}^{N} x_{i}-1\right)
$$

The first derivatives of the Lagrangrian with respect to $x_{0}$ and $x_{i}$ are

$$
\begin{aligned}
\frac{\partial L}{\partial x_{0}}= & \frac{\partial E[U(w)]}{\partial E(w)}\left(1+r_{f}\right)-\lambda=0 \\
\frac{\partial L}{\partial x_{i}}= & \frac{\partial E[U(w)]}{\partial E(w)}\left(1+E\left(r_{i}\right)\right)+\frac{\partial E[U(w)]}{\partial \sigma(w)} \beta_{i p} \sigma\left(r_{p}\right) \\
& +\frac{\partial E[U(w)]}{\partial \gamma(w)} \gamma_{i p} \gamma\left(r_{p}\right)+\frac{\partial E[U(w)]}{\partial \theta(w)} \theta_{i p} \theta\left(r_{p}\right)-\lambda \\
= & 0
\end{aligned}
$$

using $\frac{\partial E(w)}{\partial x_{i}}=1+E\left(r_{i}\right), \frac{\partial \sigma(w)}{\partial x_{i}}=\beta_{i p} \sigma\left(r_{p}\right), \frac{\partial \gamma(w)}{\partial x_{i}}=\gamma_{i p} \gamma\left(r_{p}\right)$, and $\frac{\partial \theta(w)}{\partial x_{i}}=\theta_{i p} \theta\left(r_{p}\right)$. Rearranging the equations (A2.2) and (A2.3), we obtain the following equation.

$$
E\left(r_{i}\right)-r_{f}=-\frac{\frac{\partial E[U(w)]}{\partial \sigma(w)}}{\frac{\partial E[U(w)]}{\partial E(w)}} \beta_{i p} \sigma\left(r_{p}\right)-\frac{\frac{\partial E[U(w)]}{\partial \gamma(w)}}{\frac{\partial E[U(w)]}{\partial E(w)}} \gamma_{i p} \gamma\left(r_{p}\right)-\frac{\frac{\partial E[U(w)]}{\partial \theta(w)}}{\frac{\partial E[U(w)]}{\partial E(w)}} \theta_{i p} \theta\left(r_{p}\right)
$$


In addition, since the expected utility curve of the investor is constant at the maximum, the changes in expected return and variance are zero for the given skewness and kurtosis. Using this property, the total differential of $E[U(w)]$ is set to zero, and we obtain the following equations.

$$
\begin{aligned}
& d E[U(w)]=\frac{\partial E[U(w)]}{\partial E(w)} d E(w)+\frac{\partial E[U(w)]}{\partial \sigma(w)} d \sigma(w)=0 \\
& d E[U(w)]=\frac{\partial E[U(w)]}{\partial E(w)} d E(w)+\frac{\partial E[U(w)]}{\partial \gamma(w)} d \gamma(w)=0 \\
& d E[U(w)]=\frac{\partial E[U(w)]}{\partial E(w)} d E(w)+\frac{\partial E[U(w)]}{\partial \theta(w)} d \theta(w)=0
\end{aligned}
$$

When these three equations are used for the marginal rate of substitutions in equation (A2.4), the results follow.

\section{Appendix 3}

For the logarithmic utility function, a Taylor approximation of the investor's expected utility of end of period wealth yields

$$
E[U(w)]=\log (E(w))-\frac{\sigma(w)^{2}}{2 E(w)^{2}}+\frac{\gamma(w)^{3}}{3 E(w)^{3}}-\frac{\theta(w)^{4}}{4 E(w)^{4}}
$$

Therefore,

$$
\begin{aligned}
& \frac{\partial E[U(w)]}{\partial E(w)}=\frac{1}{E(w)}+\frac{\sigma(w)^{2}}{E(w)^{3}}-\frac{\gamma(w)^{3}}{E(w)^{4}}+\frac{\theta(w)^{4}}{E(w)^{5}} \\
& \frac{\partial E[U(w)]}{\partial \sigma(w)}=-\frac{\sigma(w)}{E(w)^{2}} \\
& \frac{\partial E[U(w)]}{\partial \gamma(w)}=\frac{\gamma(w)^{2}}{E(w)^{3}} \\
& \frac{\partial E[U(w)]}{\partial \theta(w)}=-\frac{\theta(w)^{3}}{E(w)^{4}}
\end{aligned}
$$

When these equations are put into equation (A2.4), we obtain the following equation.

$$
E\left(r_{i}\right)-r_{f}=\frac{\frac{\sigma(w)}{E(w)^{2}} \beta_{i p} \sigma\left(r_{p}\right)-\frac{\gamma(w)^{2}}{E(w)^{3}} \gamma_{i p} \gamma\left(r_{p}\right)+\frac{\theta(w)^{3}}{E(w)^{4}} \theta_{i p} \theta\left(r_{p}\right)}{\frac{1}{E(w)}+\frac{\sigma(w)^{2}}{E(w)^{3}}-\frac{\gamma(w)^{3}}{E(w)^{4}}+\frac{\theta(w)^{4}}{E(w)^{5}}}
$$


Under the TFMS assumption used in this study, the above equation is

$$
E\left(r_{i}\right)-r_{f}=\frac{E\left(1+r_{m}\right)^{3} \sigma\left(r_{m}\right)^{2} \beta_{i m}-E\left(1+r_{m}\right)^{2} \gamma\left(r_{m}\right)^{3} \gamma_{i m}+E\left(1+r_{m}\right) \theta\left(r_{m}\right)^{4} \theta_{i m}}{E\left(1+r_{m}\right)^{4}+E\left(1+r_{m}\right)^{2} \sigma\left(r_{m}\right)^{2}-E\left(1+r_{m}\right) \gamma\left(r_{m}\right)^{3}+\theta\left(r_{m}\right)^{4}}
$$

since $w=w_{0}\left(1+r_{m}\right)$ and thus, $\sigma(w)=w_{0} \sigma\left(r_{m}\right), \gamma(w)=w_{0} \gamma\left(r_{m}\right)$, and $\theta(w)=w_{0} \theta\left(r_{m}\right)$.

For the market portfolio, equation (A3.7) is

$$
E\left(r_{m}\right)-r_{f}=\frac{E\left(1+r_{m}\right)^{3} \sigma\left(r_{m}\right)^{2}-E\left(1+r_{m}\right)^{2} \gamma\left(r_{m}\right)^{3}+E\left(1+r_{m}\right) \theta\left(r_{m}\right)^{4}}{E\left(1+r_{m}\right)^{4}+E\left(1+r_{m}\right)^{2} \sigma\left(r_{m}\right)^{2}-E\left(1+r_{m}\right) \gamma\left(r_{m}\right)^{3}+\theta\left(r_{m}\right)^{4}}
$$

Dividing equation (A3.7) by (A3.8), the following equation is obtained.

$$
E\left(r_{i}\right)-r_{f}=\frac{E\left(1+r_{m}\right)^{2} \sigma\left(r_{m}\right)^{2} \beta_{i m}-E\left(1+r_{m}\right) \gamma\left(r_{m}\right)^{3} \gamma_{i m}+\theta\left(r_{m}\right)^{4} \theta_{i m}}{E\left(1+r_{m}\right)^{2} \sigma\left(r_{m}\right)^{2}-E\left(1+r_{m}\right) \gamma\left(r_{m}\right)^{3}+\theta\left(r_{m}\right)^{4}}\left(E\left(r_{m}\right)-r_{f}\right)(
$$

By defining $L_{1}=\frac{E\left(1+r_{m}\right)^{2} \sigma\left(r_{m}\right)^{2}}{E\left(1+r_{m}\right)^{2} \sigma\left(r_{m}\right)^{2}-E\left(1+r_{m}\right) \gamma\left(r_{m}\right)^{3}+\theta\left(r_{m}\right)^{4}}, L_{2}=-\frac{E\left(1+r_{m}\right) \gamma\left(r_{m}\right)^{3}}{E\left(1+r_{m}\right)^{2} \sigma\left(r_{m}\right)^{2}-E\left(1+r_{m}\right) \gamma\left(r_{m}\right)^{3}+\theta\left(r_{m}\right)^{4}}$, and $L_{3}=\frac{\theta\left(r_{m}\right)^{4}}{E\left(1+r_{m}\right)^{2} \sigma\left(r_{m}\right)^{2}-E\left(1+r_{m}\right) \gamma\left(r_{m}\right)^{3}+\theta\left(r_{m}\right)^{4}}$, we obtain the following four-moment CAPM for the investor who has log-utility function.

$$
E\left(r_{i}\right)-r_{f}=\left(L_{1} \beta_{i m}+L_{2} \gamma_{i m}+L_{3} \theta_{i m}\right)\left(E\left(r_{m}\right)-r_{f}\right)
$$




\section{REFERENCES}

Arditti, F. D., 'Risk and the Required Return on Equity', Journal of Finance, 22 (1967), 19-36.

Bekaert,G., 'Exchange Rate Volatility and Deviations from Unbiasedness in a Cash-inadvance Model', Journal of International Economics, 36 (1994), 29-52.

Bekaert, G. and C. R. Harvey, 'Time-Varying World Market Integration', Journal of Finance, 50 (1995), 403-444.

Bekaert, G. and C. R. Harvey, 'Emerging Equity Market Volatility', Journal of Financial Economics, 43 (1997), 29-77.

Bekaert, G., C. B. Erb, C. R. Harvey, and T. E. Viskanta, 'What Matters for Emerging Equity Market Investments', Emerging Markets Quarterly, September (1997), 17-46.

Bekaert, G., C. B. Erb, C. R. Harvey, and T. E. Viskanta, 'Distributional Characteristics of Emerging Market Returns and Asset Allocation', Journal of Portfolio Management, Winter (1998), 102-116.

Bekaert, G. and M. S. Uris, 'Diversification, Integration and Emerging Market Closed-End Funds, Journal of Finance, 51 (1996), 835-869.

Burnside, C., 'Hansen-Jagannathan Bounds as Classical Tests of Asset-Pricing Models, Journal of Business and Economic Statistics, 12 (1994), 57-79

Fama, E., 'Multiperiod Consumption-Investment Decisions', American Economic Review, 60 (1970), 163-174.

Ferson, W. E. and S. R. Foerster, 'Finite Sample Properties of the Generalized Method of Moments in Tests of Conditional Asset Pricing Models, Journal of Financial Economics, 36 (1994), 29-55.

Friend, I. and R. Westfield, 'Co-Skewness and Capital Asset Pricing', Journal of Finance, 35 (1980), 897-919. 
Barone-Adesi, G., 'Arbitrage Equilibrium with Skewed Asset Returns', Journal of Financial and Quantitative Analysis, 20 (1985), 299-313.

Hansen, L. P., 'Large Sample Properties of Generalized Method of Moments Estimators', Econometrica, 50 (1982), 1029-54.

Heaton, J., 'An Empirical Investigation of Asset Pricing with Temporally Dependent Preference Specifications', Econometrica, 63 (1995), 681-717.

Homaifar, G. and D. B. Graddy, 'Equity Yields in Models Considering Higher Moments of the Return Distribution', Applied Economics, 20 (1988), 325-334.

Hwang, S. and S. E. Satchell, 'Evaluation of Mutual Fund Performance in Emerging Markets', Emerging Markets Quarterly, 2 (1998), 39-50.

Hwang, S. and S. E. Satchell, 'Empirical Identification of Common Factors in Emerging Markets Returns', Unpublished manuscript, Department of Applied Economics, Cambridge University, 1998.

Ingersoll, J., 'Multidimensional Security Pricing', Journal of Financial and Quantitative Analysis, 10 (1975), 785-798.

Jean, W. H., 'The Extension of Portfolio Analysis to Three or More Parameters', Journal of Financial and Quantitative Analysis, 6 (1971), 505-515.

Jean, W. H., 'More on Multidimensional Portfolio Analysis', Journal of Financial and Quantitative Analysis, 8 (1973), 475-490.

Kraus, A. and R. H. Litzenberger, 'Market Equilibrium in a Multiperiod State Preference Model with Logarithmic Utility', Journal of Finance, 30 (1975), 1213-1227.

Kraus, A. and R. H. Litzenberger, 'Skewness Preference and the Valuation of Risk Assets', Journal of Finance, 31 (1976), 1085-1100.

Kraus, A. and R. H. Litzenberger, 'On the Distributional Conditions for a Consumptionoriented Three Moment CAPM', Journal of Finance, 38 (1983), 1381-1391. 
Lim, K., 'A New Test of the Three-Moment Capital Asset Pricing Model', Journal of Financial and Quantitative Analysis, 24 (1989), 205-216.

Masters, S., 'The Problem with Emerging-Markets Indexes', Journal of Portfolio Management, Winter (1998), 93-100.

Newey, W. and K. West, 'A Simple, Positive Semi-Definite, Heteroskedasticity and Autocorrelation Consistent Covariance Matrix, Econometrica, 55 (1987), 703-708.

Scott, R. C. and P. A. Horvath, 'On the Direction of Preference for Moments of Higher Order Than the Variance', Journal of Finance, 35 (1980), 915-919.

Sears, R. S. and K. C. J. Wei, 'Asset Pricing, Higher Moments, and the Market Risk Premium: A Note', Journal of Finance, 40 (1985), 1251-1253.

Sears, R. S. and K. C. J. Wei, 'The Structure of Skewness Preferences in Asset Pricing Models with Higher Moments: An Empirical Test', Financial Review, 23 (1988), 25-38. 


\section{Table 1 Various Versions of the CAPM}

\begin{tabular}{|c|l|l|l|}
\hline Names & \multicolumn{1}{|c|}{ Models } & Equations & Subsections and Tables \\
\hline Model I & Mean-variance CAPM & Equation (37) & subsection 2.2.1 and table 5 \\
Model II & Kraus-Litzenberger Three-moment CAPM & Equation (38) & subsection 2.2.2 and table 6 \\
Model III & Kraus-Litzenberger Four-moment CAPM & Equation (11) & subsection 2.2.4 and table 8 \\
Model IV & Kraus-Litzenberger 2nd and 4th moment CAPM & Equation (40) & subsection 2.2.5 and table 9 \\
Model V & Sears-Wei Three-moment CAPM & Equation (39) & subsection 2.2.3 and table 7 \\
Model VI & Sears-Wei Four-moment CAPM & Equation (13) & $*$ \\
Model VII & Sears-Wei Four-moment CAPM with Log-utility & Equation (19) & $*$ \\
\hline
\end{tabular}

Notes : $*$ does not report results for these models because of convergence problem. 
Table 2 Statistical Properties of Emerging Markets Returns

A. The First Four Moments of Emerging Markets Monthly Returns - 87 Market Crash Included

\begin{tabular}{|c|c|c|c|c|c|}
\hline & Mean & $\begin{array}{l}\text { Standard } \\
\text { Deviation }\end{array}$ & $\begin{array}{l}\text { Normalised } \\
\text { Skewness }\end{array}$ & $\begin{array}{c}\text { Normalised } \\
\text { Excess Kurtosis }\end{array}$ & $\operatorname{Jarque-Bera}\left(\chi^{2}(2)\right)$ \\
\hline 3 Month Treasury Bill & 0.4836 & 0.1391 & -0.0582 & $-0.8356^{*}$ & 4.30 \\
\hline Market Portfolio & 0.7389 & 4.1172 & $-0.8400^{* *}$ & $3.4145^{* *}$ & $87.49^{* *}$ \\
\hline Greece & 1.0433 & 10.6924 & $0.8131^{* *}$ & $3.6292^{* *}$ & $95.55^{* *}$ \\
\hline Argentina & 1.7178 & 22.1976 & $0.3413^{*}$ & $7.9997^{* *}$ & $389.45^{* *}$ \\
\hline Brazil & 0.7965 & 18.6065 & $-0.5772^{* *}$ & $2.7326^{* *}$ & $53.16^{* *}$ \\
\hline Chile & 2.3414 & 7.5944 & -0.0525 & -0.0902 & 0.12 \\
\hline Mexico & 1.6373 & 14.1496 & $-2.5179^{* *}$ & $13.6087^{* *}$ & $1272.11^{* *}$ \\
\hline India & 0.4136 & 9.3931 & 0.2482 & 0.5015 & 3.01 \\
\hline Korea & 0.5534 & 8.0101 & 0.3289 & -0.0088 & 2.61 \\
\hline Thailand & 1.0643 & 8.9447 & $-0.8012^{* *}$ & $3.5682^{* *}$ & $92.43^{* *}$ \\
\hline Zimbabwe & 1.7897 & 8.7361 & 0.1766 & $2.2272^{* *}$ & $30.72^{* *}$ \\
\hline Jordan & 0.0796 & 4.6921 & 0.1068 & $1.1560^{* *}$ & $8.35^{*}$ \\
\hline Colombia & 1.9170 & 8.0836 & $1.1363^{* *}$ & $2.6627^{* *}$ & $74.04^{* *}$ \\
\hline Venezuela & 0.7336 & 14.1033 & $-1.3266^{* *}$ & $6.1726^{* *}$ & $272.72^{* *}$ \\
\hline Taiwan & 1.2000 & 13.5401 & -0.1512 & $1.8391^{* *}$ & $20.99^{* *}$ \\
\hline Malaysia & 0.5891 & 7.5910 & $-0.9332^{* *}$ & $3.5182^{* *}$ & $95.83^{* *}$ \\
\hline Pakistan & 0.5060 & 6.9609 & $0.7881^{* *}$ & $3.6939^{* *}$ & $97.45^{* *}$ \\
\hline Philippines & 2.2517 & 9.7324 & 0.0456 & $2.6773^{* *}$ & $43.36^{* *}$ \\
\hline Nigeria & 0.0543 & 16.6513 & $-3.1868^{* *}$ & $25.2309^{* * *}$ & $4091.56^{* * *}$ \\
\hline
\end{tabular}

B. The First Four Moments of Emerging Markets Monthly Returns - 87 Market Crash Excluded

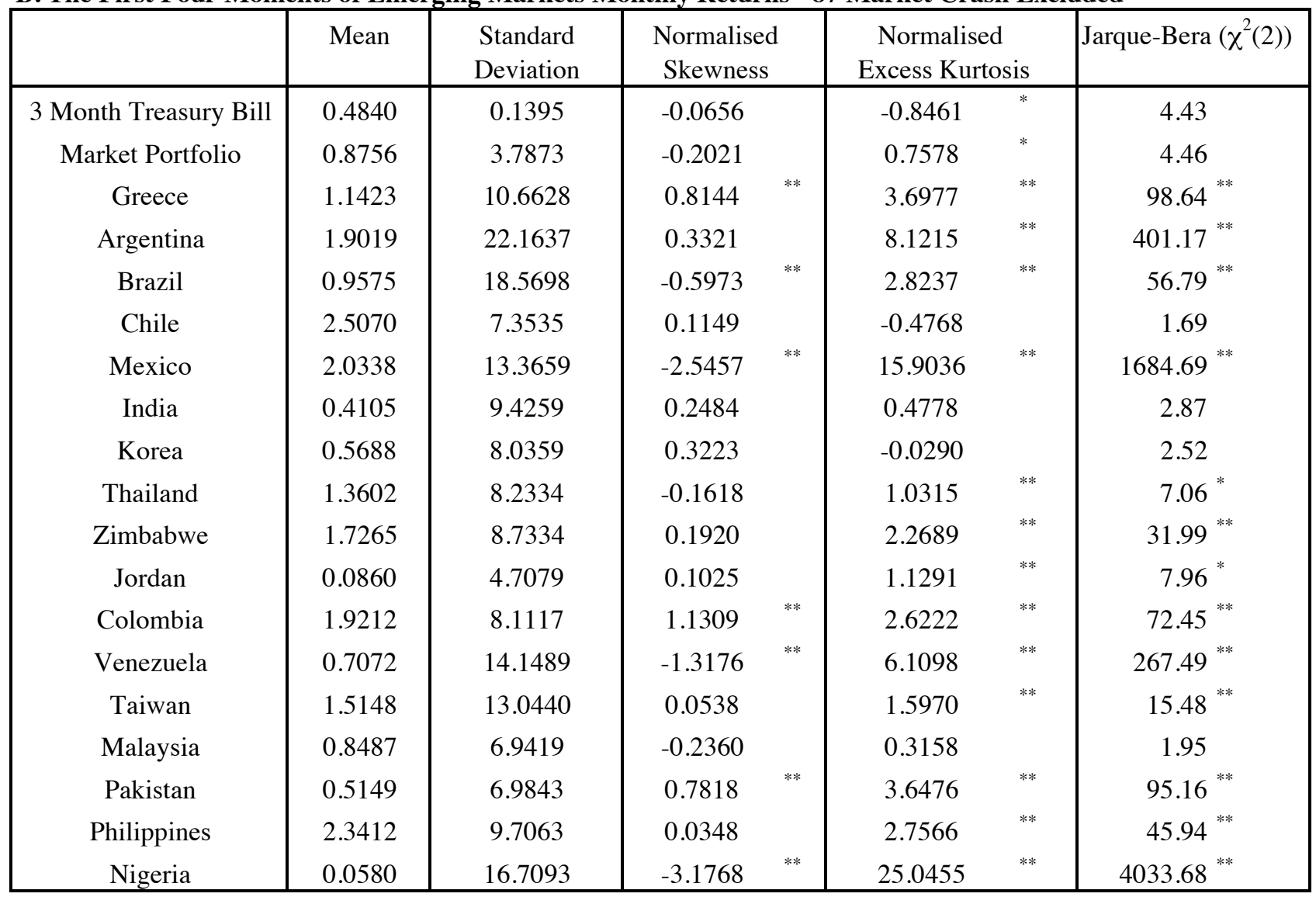

Notes: $*$ denotes siginificance at $5 \%$ level and $* *$ denotes siginificance at $1 \%$ level.

Morgan Stanley world index is used for the market portfolio. Deflated excess returns are used for the market portfolio and emerging markets 


\section{Table 3 GMM Estimates of the Marginal Rates of Substitution}

\section{A. Three-moment CAPM}

\begin{tabular}{|c|c|c|c|c|}
\hline & & & Estimates & Normalised \\
\hline \multirow{6}{*}{ Market Crash of October 1987 Included } & & Mean of Market Portfolio & 0.8475 & \multirow{6}{*}{$\begin{array}{r}-1.5855 \\
8.3215\end{array}$} \\
\hline & Sample Estimates & Standard Deviation of Market Portfolio & 4.2001 & \\
\hline & & Skewness of Market Portfolio & -4.8976 & \\
\hline & & Kurtosis of Market Portfolio & 7.7044 & \\
\hline & GMM Estimates & Marginal Rate of Substitution Between Skewness and Risk $\left(\mathrm{k}_{1}\right)$ & $-0.1266 \quad(1.4736)$ & \\
\hline & \multicolumn{2}{|c|}{ Lagrange Multiplier Statistics $-\chi^{2}(22)$} & 16.9016 & \\
\hline \multirow{6}{*}{ Market Crash of October 1987 Excluded } & & Mean of Market Portfolio & 1.0239 & \multirow{6}{*}{$\begin{array}{r}-0.2397 \\
0.7849\end{array}$} \\
\hline & Sample Estimates & Standard Deviation of Market Portfolio & 3.6406 & \\
\hline & & Skewness of Market Portfolio & -2.2615 & \\
\hline & & Kurtosis of Market Portfolio & 5.0779 & \\
\hline & GMM Estimates & Marginal Rate of Substitution Between Skewness and Risk $\left(\mathrm{k}_{1}\right)$ & $0.1693 \quad(0.2574)$ & \\
\hline & \multicolumn{2}{|c|}{ Lagrange Multiplier Statistics $-\chi^{2}(22)$} & 24.2233 & \\
\hline
\end{tabular}

Notes : The three-moment CAPM in equation (30) is used for the GMM estimate of $\mathrm{k}_{1}$. Chi-Square (22) statistics at $10 \%$ is 30.8 .

Values in parenthesis are the standard errors of the estimates. Values in the 'normalised' column are sample etimated normalised skewness and normalised excess kurtosis.

\section{B. Four-moment CAPM}

\begin{tabular}{|c|c|c|c|c|}
\hline & & & Estimates & \\
\hline \multirow{3}{*}{ Market Crash of October 1987 Included } & \multirow[t]{2}{*}{ GMM Estimates } & Marginal Rate of Substitution Between Skewness and Risk $\left(\mathrm{k}_{1}\right)$ & -3.7964 & $(5.9402)$ \\
\hline & & Marginal Rate of Substitution Between Kurtosis and Risk $\left(\mathrm{k}_{2}\right)$ & -2.7887 & $(4.0337)$ \\
\hline & \multicolumn{2}{|c|}{ Lagrange Multiplier Statistics $-\chi^{2}(23)$} & 20.1909 & \\
\hline \multirow{3}{*}{ Market Crash of October 1987 Excluded } & \multirow[t]{2}{*}{ GMM Estimates } & Marginal Rate of Substitution Between Skewness and Risk $\left(\mathrm{k}_{1}\right)$ & -0.3047 & $(2.0027)$ \\
\hline & & Marginal Rate of Substitution Between Kurtosis and Risk $\left(\mathrm{k}_{2}\right)$ & -1.6856 & $(7.3457)$ \\
\hline & \multicolumn{2}{|c|}{ Lagrange Multiplier Statistics $-\chi^{2}(23)$} & 25.8026 & \\
\hline
\end{tabular}

Notes : The four-moment CAPM in equation (13) is used for the GMM estimates of $\mathrm{k}_{1}$ and $\mathrm{k}_{2}$. Chi-Square (23) statistics at $10 \%$ is 32.0 . 
Table 4 Correlation Matrix between $\beta_{\mathrm{im}}, \gamma_{\mathrm{im}}$, and $\theta_{\mathrm{im}}$

A. Market Crash of October 1987 Included

\begin{tabular}{|c|ccc|}
\hline & $\beta_{\text {im }}$ & $\gamma_{\text {im }}$ & $\theta_{\text {im }}$ \\
\hline$\beta_{\text {im }}$ & 1 & & \\
$\gamma_{\text {im }}$ & 0.6673 & 1 & \\
$\theta_{\text {im }}$ & 0.8873 & 0.8826 & 1 \\
\hline
\end{tabular}

A. Market Crash of October 1987 Excluded

\begin{tabular}{|c|ccc|}
\hline & $\beta_{\text {im }}$ & $\gamma_{\text {im }}$ & $\theta_{\text {im }}$ \\
\hline$\beta_{\text {im }}$ & 1 & & \\
$\gamma_{\text {im }}$ & 0.2612 & 1 & \\
$\theta_{\text {im }}$ & 0.9386 & 0.3712 & 1 \\
\hline
\end{tabular}


Table 5 GMM Estimates of Mean-variance CAPM

\section{A. Market Crash of October 1987 Included}

\begin{tabular}{|c|c|c|c|c|c|}
\hline & Countries & \multicolumn{2}{|c|}{ Beta } & $\begin{array}{c}\text { Lagrange Multiplier Test } \\
\text { Chi-Square }\end{array}$ & $\begin{array}{l}\text { Adjusted } \\
R \text {-Square }\end{array}$ \\
\hline $\begin{array}{l}\text { Latin } \\
\text { America }\end{array}$ & $\begin{array}{c}\text { Argentina } \\
\text { Brazil } \\
\text { Chile } \\
\text { Mexico } \\
\text { Colombia } \\
\text { Venezuela }\end{array}$ & $\begin{array}{r}-0.1661 \\
0.6249 \\
0.4009 \\
1.3657 \\
0.1485 \\
-0.3096\end{array}$ & $\begin{array}{l}(0.5596) \\
(0.4223) \\
(0.1865) \\
(0.3066) \\
(0.1481) \\
(0.2746)\end{array}{ }^{* *}$ & $\begin{array}{r}19.2529 \\
\text { (Degrees of Freedom: 6) }\end{array}$ & 0.0899 \\
\hline Asia & $\begin{array}{c}\text { India } \\
\text { Korea } \\
\text { Thailand } \\
\text { Taiwan } \\
\text { Malaysia } \\
\text { Pakistan } \\
\text { Philippines }\end{array}$ & $\begin{array}{r}-0.2277 \\
0.6023 \\
0.8235 \\
0.8252 \\
0.8107 \\
0.0799 \\
0.9535\end{array}$ & $\begin{array}{l}(0.1776) \\
(0.1558) \\
(0.2392) \\
(0.3287) \\
(0.1910) \\
(0.1266) \\
(0.2261)^{* *}\end{array}{ }^{* *}$ & $\begin{array}{r}5.8164 \\
\text { (Degrees of Freedom: } 7 \text { ) }\end{array}$ & 0.2149 \\
\hline $\begin{array}{c}\text { Other } \\
\text { Countries }\end{array}$ & $\begin{array}{c}\text { Greece } \\
\text { Zimbabwe } \\
\text { Jordan } \\
\text { Nigeria }\end{array}$ & $\begin{array}{l}0.4482 \\
0.1971 \\
0.1385 \\
0.3122\end{array}$ & $\begin{array}{l}(0.2126) \\
(0.1842) \\
(0.1049) \\
(0.3102)\end{array}$ & $\begin{array}{r}5.9612 \\
\text { (Degrees of Freedom: 4) }\end{array}$ & 0.0464 \\
\hline
\end{tabular}

B. Market Crash of October 1987 Excluded

\begin{tabular}{|c|c|c|c|c|c|}
\hline & Countries & \multicolumn{2}{|c|}{ Beta } & $\begin{array}{c}\text { Lagrange Multiplier Test } \\
\text { Chi-Square }\end{array}$ & $\begin{array}{l}\text { Adjusted } \\
R \text {-Square }\end{array}$ \\
\hline $\begin{array}{l}\text { Latin } \\
\text { America }\end{array}$ & $\begin{array}{c}\text { Argentina } \\
\text { Brazil } \\
\text { Chile } \\
\text { Mexico } \\
\text { Colombia } \\
\text { Venezuela }\end{array}$ & $\begin{array}{r}-0.4721 \\
0.5455 \\
0.1895 \\
0.8529 \\
0.2254 \\
-0.4059\end{array}$ & $\begin{array}{l}(0.6014) \\
(0.4838) \\
(0.1647) \\
(0.2221) \\
(0.1711) \\
(0.3150)\end{array}$ & $\begin{array}{r}23.3978 \\
\text { (Degrees of Freedom: 6) }\end{array}$ & 0.0591 \\
\hline Asia & $\begin{array}{c}\text { India } \\
\text { Korea } \\
\text { Thailand } \\
\text { Taiwan } \\
\text { Malaysia } \\
\text { Pakistan } \\
\text { Philippines }\end{array}$ & $\begin{array}{r}-0.2345 \\
0.6753 \\
0.7052 \\
0.7349 \\
0.6934 \\
0.0970 \\
1.0701\end{array}$ & $\begin{array}{l}(0.2036) \\
(0.1574) \\
(0.1922) \\
(0.3318) \\
(0.1541) \\
(0.1475) \\
(0.2538)\end{array}$ *** ${ }^{* *}$ & $\begin{array}{r}5.0968 \\
\text { (Degrees of Freedom: } 7 \text { ) }\end{array}$ & 0.2163 \\
\hline $\begin{array}{c}\text { Other } \\
\text { Countries }\end{array}$ & $\begin{array}{c}\text { Greece } \\
\text { Zimbabwe } \\
\text { Jordan } \\
\text { Nigeria }\end{array}$ & $\begin{array}{l}0.4365 \\
0.3149 \\
0.1490 \\
0.3395\end{array}$ & $\begin{array}{l}(0.2444) \\
(0.1907) \\
(0.1197) \\
(0.3677)\end{array}$ & $\begin{array}{r}4.9969 \\
\text { (Degrees of Freedom: 4) }\end{array}$ & 0.0750 \\
\hline
\end{tabular}

Notes: $* *$ denotes significance at $1 \%$ and $*$ denotes significance at $5 \%$.

Numbers in parentheses are standard errors. The CAPM estimated is

$$
E\left(R_{i}\right)-r_{f}=\left(E\left(R_{m}\right)-r_{f}\right) \beta_{i}
$$


Table 6 GMM Estimates of Kraus-Litzenberger Three-Moment CAPM

\section{A. Market Crash of October 1987 Included}

\begin{tabular}{|c|c|c|c|c|c|c|c|c|c|}
\hline & \multirow[t]{2}{*}{ Countries } & \multirow{2}{*}{\multicolumn{2}{|c|}{ Beta }} & \multirow{2}{*}{\multicolumn{2}{|c|}{ Co-skewness }} & \multicolumn{2}{|c|}{ Kraus-Litzenberger (1976) } & \multirow{2}{*}{$\begin{array}{c}\text { Lagrange Multiplier Test } \\
\text { Chi-Square }\end{array}$} & \multirow{2}{*}{$\begin{array}{l}\text { Adjusted } \\
R \text {-Square }\end{array}$} \\
\hline & & & & & & $\alpha_{1}$ & $\alpha_{2}$ & & \\
\hline $\begin{array}{c}\text { Latin } \\
\text { America }\end{array}$ & $\begin{array}{c}\text { Argentina } \\
\text { Brazil } \\
\text { Chile } \\
\text { Mexico } \\
\text { Colombia } \\
\text { Venezuela }\end{array}$ & $\begin{array}{c}-0.3605 \\
0.4892 \\
0.3032 \\
1.1198 \\
0.1571 \\
-0.2132\end{array}$ & $\begin{array}{l}(0.5655) \\
(0.4292) \\
(0.1974) \\
(0.3616) \\
(0.1512) \\
(0.2752)\end{array}$ & $\begin{array}{r}4.3880 \\
3.2379 \\
1.9471 \\
4.1734 \\
0.0408 \\
-1.4043\end{array}$ & $\begin{array}{l}(1.5129) \\
(1.2170) \\
(0.9131) \\
(2.0827) \\
(0.1745) \\
(0.5494)\end{array}$ & $\begin{array}{r}0.6526 \\
(1.3011)\end{array}$ & $\begin{array}{r}0.2851 \\
(0.3292)\end{array}$ & $\begin{array}{r}14.0651 \\
\text { (Degrees of Freedom: 4) }\end{array}$ & 0.3089 \\
\hline Asia & $\begin{array}{c}\text { India } \\
\text { Korea } \\
\text { Thailand } \\
\text { Taiwan } \\
\text { Malaysia } \\
\text { Pakistan } \\
\text { Philippines }\end{array}$ & $\begin{array}{r}-0.1986 \\
0.5713 \\
0.8287 \\
0.8684 \\
0.8065 \\
0.0829 \\
0.9897\end{array}$ & $\begin{array}{l}(0.1722) \\
(0.1577)^{\text {** }} \\
(0.2788)^{\text {** }} \\
(0.3680)^{\text {** }} \\
(0.2127)^{\text {** }} \\
(0.1226)^{\text {* }} \\
(0.2244)^{\text {** }}\end{array}$ & $\begin{array}{r}-0.1989 \\
0.0161 \\
2.6818 \\
2.9329 \\
2.1808 \\
-0.0928 \\
1.6814\end{array}$ & $\begin{array}{l}(0.3136) \\
(0.2633) \\
(2.4250) \\
(2.6610) \\
(2.0532) \\
(0.1590) \\
(1.2023)\end{array}$ & $\begin{array}{r}1.3524 \\
(0.9992)\end{array}$ & $\begin{array}{r}-0.1615 \\
(0.3805)\end{array}$ & $\begin{array}{r}4.9826 \\
\text { (Degrees of Freedom: 5) }\end{array}$ & 0.2558 \\
\hline $\begin{array}{c}\text { Other } \\
\text { Countries }\end{array}$ & $\begin{array}{c}\text { Greece } \\
\text { Zimbabwe } \\
\text { Jordan } \\
\text { Nigeria }\end{array}$ & $\begin{array}{l}0.4510 \\
0.1390 \\
0.1247 \\
0.0810\end{array}$ & $\begin{array}{l}(0.2069) \\
(0.1861) \\
(0.0949) \\
(0.2645)\end{array}$ & $\begin{array}{r}0.6977 \\
-0.4539 \\
0.2337 \\
-0.1446\end{array}$ & $\begin{array}{l}(0.7244) \\
(0.4749) \\
(0.2271) \\
(0.2484)\end{array}$ & $\begin{array}{r}4.8183 \\
(3.7150)\end{array}$ & $\begin{array}{l}-1.9001 \\
(1.9751)\end{array}$ & $\begin{array}{r}0.9416 \\
\text { (Degrees of Freedom: 2) }\end{array}$ & 0.7319 \\
\hline
\end{tabular}

B. Market Crash of October 1987 Excluded

\begin{tabular}{|c|c|c|c|c|c|c|c|c|}
\hline & \multirow[t]{2}{*}{ Countries } & \multirow{2}{*}{\multicolumn{2}{|c|}{ Beta }} & \multirow[t]{2}{*}{ Co-skewness } & \multicolumn{2}{|c|}{ Kraus-Litzenberger (1976) } & \multirow{2}{*}{$\begin{array}{c}\text { Lagrange Multiplier Test } \\
\text { Chi-Square }\end{array}$} & \multirow{2}{*}{$\begin{array}{l}\text { Adjusted } \\
R \text {-Square }\end{array}$} \\
\hline & & & & & $\alpha_{1}$ & $\alpha_{2}$ & & \\
\hline $\begin{array}{c}\text { Latin } \\
\text { America }\end{array}$ & $\begin{array}{c}\text { Argentina } \\
\text { Brazil } \\
\text { Chile } \\
\text { Mexico } \\
\text { Colombia } \\
\text { Venezuela }\end{array}$ & $\begin{array}{r}-0.2776 \\
0.3154 \\
0.2973 \\
0.6910 \\
0.3046 \\
-0.1054\end{array}$ & $\begin{array}{l}(0.6024) \\
(0.4508) \\
(0.1630) \\
(0.2371) \\
(0.1567) \\
(0.2892)\end{array}$ & $\begin{array}{rr}10.7892 & (12.1322) \\
6.7817 & (8.0795) \\
1.4210 & (1.8135) \\
1.4938 & (2.2841) \\
0.1381 & (1.2004) \\
-5.3016 & (6.5286)\end{array}$ & $\begin{array}{r}2.2005 \\
(1.5568)\end{array}$ & $\begin{array}{r}0.1534 \\
(0.2531)\end{array}$ & $\begin{array}{r}15.7981 \\
\text { (Degrees of Freedom: 3) }\end{array}$ & 0.3696 \\
\hline Asia & $\begin{array}{c}\text { India } \\
\text { Korea } \\
\text { Thailand } \\
\text { Taiwan } \\
\text { Malaysia } \\
\text { Pakistan } \\
\text { Philippines }\end{array}$ & $\begin{array}{r}-0.2273 \\
0.6553 \\
0.6048 \\
0.5482 \\
0.6569 \\
0.0966 \\
0.9045\end{array}$ & $\begin{array}{l}(0.2006) \\
(0.1588) \\
(0.2112)^{\text {** }} \\
(0.3441) \\
(0.1602)^{\text {** }} \\
(0.1465) \\
(0.2766)^{\text {** }}\end{array}$ & $\begin{aligned}-0.1251 & (1.1785) \\
-0.4719 & (1.0729) \\
4.3329 & (5.3127) \\
5.1181 & (6.4922) \\
2.9922 & (3.7053) \\
-0.3278 & (0.6964) \\
5.2197 & (6.5957)\end{aligned}$ & $\begin{array}{r}1.0084 \\
(0.8485)\end{array}$ & $\begin{array}{r}0.1327 \\
(0.2458)\end{array}$ & $\begin{array}{r}2.8400 \\
\text { (Degrees of Freedom: 5) }\end{array}$ & 0.5609 \\
\hline $\begin{array}{c}\text { Other } \\
\text { Countries }\end{array}$ & $\begin{array}{c}\text { Greece } \\
\text { Zimbabwe } \\
\text { Jordan } \\
\text { Nigeria }\end{array}$ & $\begin{array}{l}0.3322 \\
0.3521 \\
0.0835 \\
0.2069\end{array}$ & $\begin{array}{l}(0.2205) \\
(0.1787) \\
(0.1141) \\
(0.3502)\end{array}$ & $\begin{aligned}-0.1184 & (2.8129) \\
0.4599 & (1.4982) \\
0.9390 & (2.2144) \\
-1.1654 & (2.4932)\end{aligned}$ & $\begin{array}{r}3.0577 \\
(2.2279)\end{array}$ & $\begin{array}{r}0.0562 \\
(0.5678)\end{array}$ & $\begin{array}{r}2.1532 \\
\text { (Degrees of Freedom: 2) }\end{array}$ & 0.4252 \\
\hline
\end{tabular}

Notes: ** denotes significance at $1 \%$ and $*$ denotes significance at $5 \%$. Numbers in parentheses are standard errors. The three-moment CAPM estimated is $E\left(R_{i}\right)-r_{f}=\alpha_{1} \beta_{i}+\alpha_{2} \gamma_{i}$ 
Table 7 GMM Estimates of the Sears-Wei Three-Moment CAPM

A. Market Crash of October 1987 Included

\begin{tabular}{|c|c|c|c|c|c|c|}
\hline & Countries & \multicolumn{2}{|c|}{ Beta } & Co-skewness & Marginal Rate of & Lagrange Multiplier Test \\
\hline $\begin{array}{l}\text { Latin } \\
\text { America }\end{array}$ & $\begin{array}{c}\text { Argentina } \\
\text { Brazil } \\
\text { Chile } \\
\text { Mexico } \\
\text { Colombia } \\
\text { Venezuela }\end{array}$ & $\begin{array}{r}-0.2352 \\
0.5810 \\
0.2997 \\
1.2170 \\
0.0838 \\
-0.3093\end{array}$ & $\begin{array}{l}(0.5592) \\
(0.4223) \\
(0.1848) \\
(0.2890) \\
(0.1491) \\
(0.2731)\end{array}$ & $\begin{aligned} 3.0413 & (1.5962) \\
2.4827 & (1.3035) \\
1.2873 & (0.9725) \\
2.6217 & (2.2558) \\
-0.0162 & (0.2215) \\
-1.1109 & (0.6244)\end{aligned}$ * & -0.0762 & $\begin{array}{c}18.3257^{* *} \\
\text { (Degrees of Freedom: 6) }\end{array}$ \\
\hline Asia & $\begin{array}{c}\text { India } \\
\text { Korea } \\
\text { Thailand } \\
\text { Taiwan } \\
\text { Malaysia } \\
\text { Pakistan } \\
\text { Philippines }\end{array}$ & $\begin{array}{r}-0.2113 \\
0.8426 \\
0.3098 \\
0.3307 \\
0.3918 \\
0.1498 \\
0.7566 \\
\end{array}$ & $\begin{array}{l}(0.1528) \\
(0.1231) \\
(0.1252) \\
(0.2147) \\
(0.1090) \\
(0.1028) \\
(0.2057)^{* *}\end{array}$ & $\begin{aligned} & 0.3623(27.1801) \\
&-1.4376(33.1106) \\
& 3.0454(35.9829) \\
& 3.6698(49.8408) \\
& 1.9604(29.3719) \\
&-0.6788(21.5858) \\
& 6.2330(65.7401) \\
&\end{aligned}$ & -0.0762 & $\begin{array}{c}33.2984 \\
\text { (Degrees of Freedom: 7) }\end{array}$ \\
\hline $\begin{array}{c}\text { Other } \\
\text { Countries }\end{array}$ & $\begin{array}{c}\text { Greece } \\
\text { Zimbabwe } \\
\text { Jordan } \\
\text { Nigeria }\end{array}$ & $\begin{array}{l}0.4248 \\
0.2131 \\
0.1317 \\
0.3066\end{array}$ & $\begin{array}{l}(0.2122) \\
(0.1836) \\
(0.1048) \\
(0.3075)\end{array}$ & $\begin{aligned} 0.5103 & (1.1966) \\
-0.2746 & (0.7604) \\
0.2565 & (0.4019) \\
-0.0837 & (0.4896)\end{aligned}$ & -0.0762 & $\begin{array}{c}5.9314 \\
\text { (Degrees of Freedom: 4) }\end{array}$ \\
\hline
\end{tabular}

\section{B. Market Crash of October 1987 Excluded}

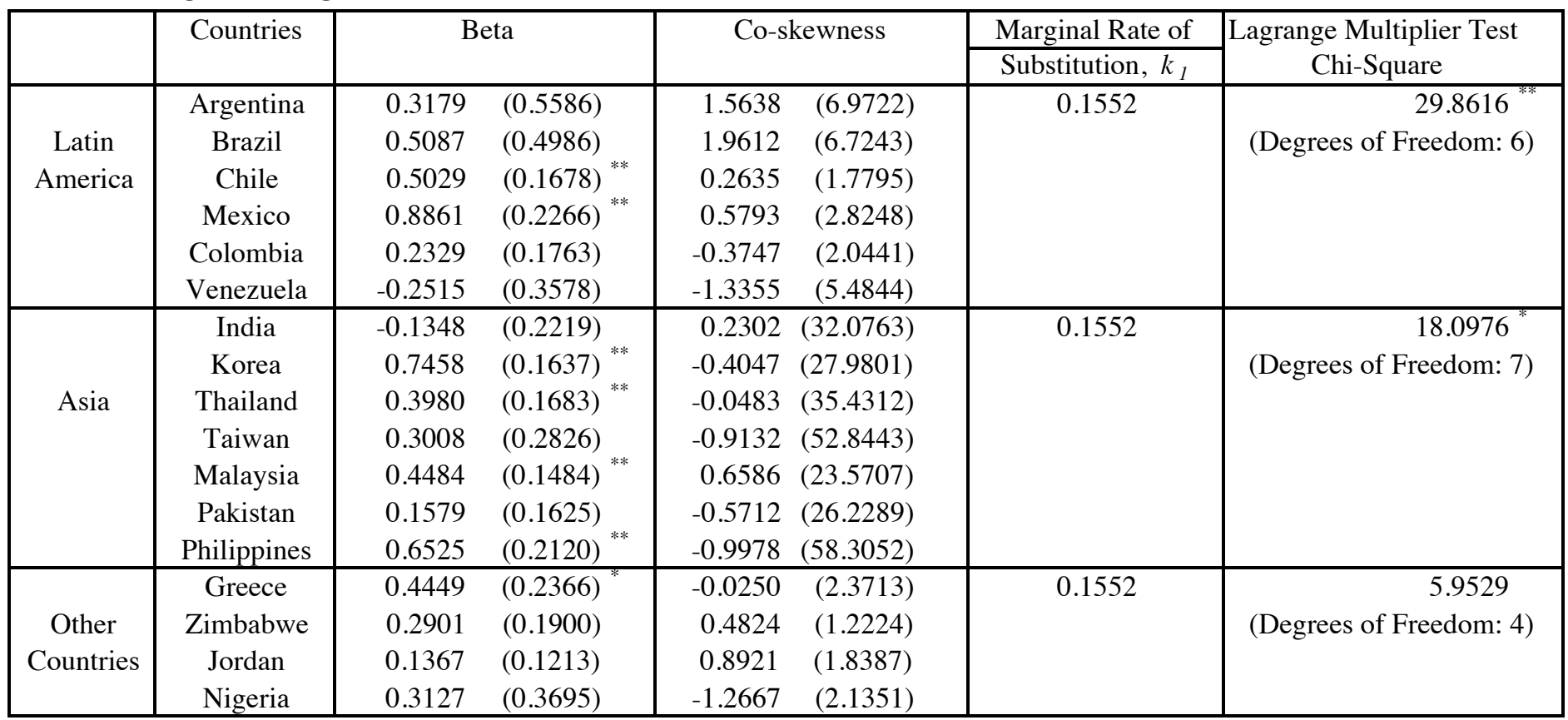

Notes: $* *$ denotes significance at $1 \%$ and * denotes significance at $5 \%$. Numbers in parentheses are standard errors.

The three-moment CAPM estimated is

$$
E\left(R_{i}\right)-r_{f}=\left(\frac{\sigma\left(R_{m}\right)}{\sigma\left(R_{m}\right)+k_{1} \gamma\left(R_{m}\right)} \beta_{i}+\frac{k_{1} \gamma\left(R_{m}\right)}{\sigma\left(R_{m}\right)+k_{1} \gamma\left(R_{m}\right)} \gamma_{i}\right)\left(E\left(R_{m}\right)-r_{f}\right)
$$


Table 8 GMM Estimates of Kraus-Litzenberger Four-Moment CAPM

A. Market Crash of October 1987 Included

\begin{tabular}{|c|c|c|c|c|c|c|c|c|c|c|c|c|}
\hline & \multirow[t]{2}{*}{ Countries } & \multirow{2}{*}{\multicolumn{2}{|c|}{ Beta }} & \multirow{2}{*}{\multicolumn{2}{|c|}{ Co-skewness }} & \multirow{2}{*}{\multicolumn{2}{|c|}{ Co-kurtosis }} & \multicolumn{3}{|c|}{ Kraus-Litzenberger (1976) } & \multirow{2}{*}{$\begin{array}{c}\text { Lagrange Multiplier Test } \\
\text { Chi-Square }\end{array}$} & \multirow{2}{*}{$\begin{array}{l}\text { Adjusted } \\
R \text {-Square }\end{array}$} \\
\hline & & & & & & & & $\alpha_{1}$ & $\alpha_{2}$ & $\alpha_{3}$ & & \\
\hline $\begin{array}{l}\text { Latin } \\
\text { America }\end{array}$ & $\begin{array}{c}\text { Argentina } \\
\text { Brazil } \\
\text { Chile } \\
\text { Mexico } \\
\text { Colombia } \\
\text { Venezuela }\end{array}$ & $\begin{array}{r}-0.2735 \\
0.3982 \\
0.1105 \\
1.0021 \\
-0.0212 \\
-0.2681\end{array}$ & $\begin{array}{l}(0.5445) \\
(0.3912) \\
(0.1661) \\
(0.2962) \\
(0.1537) \\
(0.2604)\end{array}$ & $\begin{array}{r}2.4148 \\
2.2398 \\
0.8044 \\
1.4360 \\
-0.0325 \\
-0.9959 \\
\end{array}$ & $\begin{array}{l}(1.9374) \\
(1.6816) \\
(1.0366) \\
(2.2327) \\
(0.3551) \\
(0.9525)\end{array}$ & $\begin{array}{r}0.3097 \\
0.8111 \\
0.5503 \\
1.7245 \\
0.1882 \\
-0.3833 \\
\end{array}$ & $\begin{array}{l}(0.6350) \\
(0.3510) \\
(0.3220) \\
(0.6178) \\
(0.1326) \\
(0.2704)\end{array}$ & $\begin{array}{l}-6.8755^{\circ} \\
(3.8163)\end{array}$ & $\begin{array}{r}-0.9120 \\
(1.0850)\end{array}$ & $\begin{array}{c}6.1857^{*} \\
(2.9170)\end{array}$ & $\begin{array}{r}4.0432 \\
\text { (Degrees of Freedom: 3) }\end{array}$ & 0.8680 \\
\hline Asia & $\begin{array}{c}\text { India } \\
\text { Korea } \\
\text { Thailand } \\
\text { Taiwan } \\
\text { Malaysia } \\
\text { Pakistan } \\
\text { Philippines }\end{array}$ & $\begin{array}{r}-0.2122 \\
0.6037 \\
0.8216 \\
0.8749 \\
0.8391 \\
0.1055 \\
0.8401\end{array}$ & $\begin{array}{l}(0.1747) \\
(0.1514)^{* *} \\
(0.2777)^{* *} \\
(0.3594)^{* *} \\
(0.2161)^{* *} \\
(0.1116)^{* *} \\
(0.2273)^{* *}\end{array}$ & $\begin{array}{r}-0.0521 \\
-0.0255 \\
2.7040 \\
2.9871 \\
2.2161 \\
-0.0292 \\
1.4389\end{array}$ & $\begin{array}{l}(0.2335) \\
(0.2409) \\
(2.3255) \\
(2.5386) \\
(1.9793) \\
(0.1367) \\
(1.0576)\end{array}$ & $\begin{array}{r}-0.1913 \\
0.3438 \\
1.6346 \\
1.7828 \\
1.4644 \\
0.0332 \\
0.9744\end{array}$ & $\left.\begin{array}{l}(0.1187) \\
(0.1221) \\
(0.4367) \\
(0.4721)^{* * *} \\
(0.3629) \\
(0.0456) \\
(0.2433)\end{array}\right)^{* *}$ & $\begin{array}{r}6.2822 \\
(7.0614)\end{array}$ & $\begin{array}{r}3.9333 \\
(6.0249)\end{array}$ & $\begin{array}{r}-9.1157 \\
(12.3959)\end{array}$ & $\begin{array}{r}0.9240 \\
\text { (Degrees of Freedom: 4) }\end{array}$ & 0.7403 \\
\hline $\begin{array}{l}\text { Other } \\
\text { Countries }\end{array}$ & $\begin{array}{c}\text { Greece } \\
\text { Zimbabwe } \\
\text { Jordan } \\
\text { Nigeria }\end{array}$ & $\begin{array}{l}0.4672 \\
0.1448 \\
0.1057 \\
0.1033\end{array}$ & $\begin{array}{l}(0.2131) \\
(0.1868) \\
(0.1023) \\
(0.2904)\end{array}$ & $\begin{array}{r}0.5608 \\
-0.3589 \\
0.2110 \\
-0.1922\end{array}$ & $\begin{array}{l}(0.8149) \\
(0.5195) \\
(0.2537) \\
(0.3040)\end{array}$ & $\begin{array}{r}0.7609 \\
-0.2637 \\
0.1265 \\
0.1556\end{array}$ & $\begin{array}{l}(0.1299) \\
(0.1623) \\
(0.0928) \\
(0.1296)\end{array}$ & $\begin{array}{r}5.8229 \\
(4.1364)\end{array}$ & $\begin{array}{r}-0.7827 \\
(4.0986)\end{array}$ & $\begin{array}{r}-1.9953 \\
(4.6666)\end{array}$ & $\begin{array}{r}0.8560 \\
\text { (Degrees of Freedom: } 1)\end{array}$ & 0.7343 \\
\hline
\end{tabular}

\section{B. Market Crash of October 1987 Excluded}

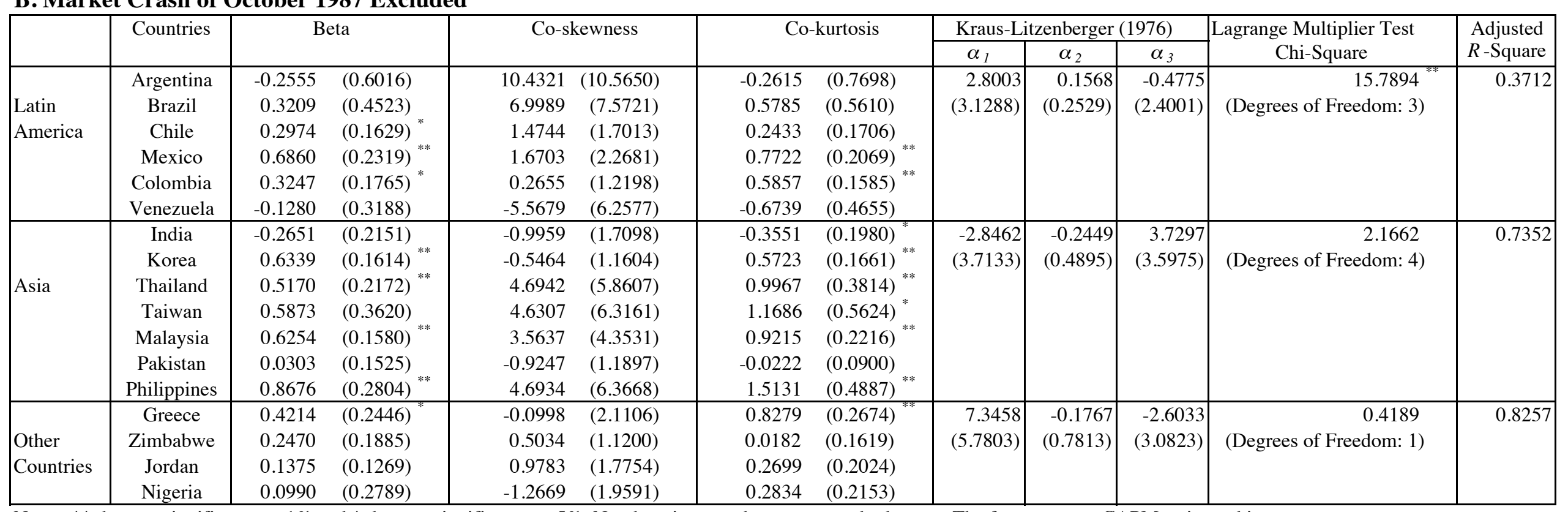

Notes: $* *$ denotes significance at $1 \%$ and $*$ denotes significance at $5 \%$. Numbers in parentheses are standard errors. The four-moment CAPM estimated is

$E\left(R_{i}\right)-r_{f}=\alpha_{1} \beta_{i}+\alpha_{2} \gamma_{i}+\alpha_{3} \theta_{i}$ 
Table 9 GMM Estimates of Kraus-Litzenberger Second- and Fourth-Moment CAPM

A. Market Crash of October 1987 Included

\begin{tabular}{|c|c|c|c|c|c|c|c|c|c|}
\hline & \multirow[t]{2}{*}{ Countries } & \multirow{2}{*}{\multicolumn{2}{|c|}{ Beta }} & \multirow{2}{*}{\multicolumn{2}{|c|}{ Co-kurtosis }} & \multicolumn{2}{|c|}{ Kraus-Litzenberger (1976) } & \multirow{2}{*}{$\begin{array}{c}\text { Lagrange Multiplier Test } \\
\text { Chi-Square }\end{array}$} & \multirow{2}{*}{$\begin{array}{r}\text { Adjusted } \\
R \text {-Square } \\
\end{array}$} \\
\hline & & & & & & $\alpha_{1}$ & $\alpha_{3}$ & & \\
\hline $\begin{array}{l}\text { Latin } \\
\text { America }\end{array}$ & $\begin{array}{c}\text { Argentina } \\
\text { Brazil } \\
\text { Chile } \\
\text { Mexico } \\
\text { Colombia } \\
\text { Venezuela } \\
\end{array}$ & $\begin{array}{r}-0.1266 \\
0.5943 \\
0.1127 \\
0.9465 \\
-0.0414 \\
-0.3756 \\
\end{array}$ & $\begin{array}{l}(0.4831) \\
(0.3460) \\
(0.1569) \\
(0.2635) \\
(0.1523) \\
(0.2658)\end{array}$ & $\begin{array}{r}0.3770 \\
0.9074 \\
0.5460 \\
1.6870 \\
0.1997 \\
-0.4609 \\
\end{array}$ & $\begin{array}{l}(0.6129) \\
(0.3443) \\
(0.2926) \\
(0.5457) \\
(0.1251) \\
(0.2736)\end{array}{ }^{*}$ & $\begin{array}{r}-5.3487 \\
(2.9863)\end{array}$ & $\begin{array}{r}4.2478 \\
(2.2005)\end{array}$ & $\begin{array}{r}6.1082 \\
\text { (Degrees of Freedom: 4) }\end{array}$ & 0.8593 \\
\hline Asia & $\begin{array}{c}\text { India } \\
\text { Korea } \\
\text { Thailand } \\
\text { Taiwan } \\
\text { Malaysia } \\
\text { Pakistan } \\
\text { Philippines }\end{array}$ & $\begin{array}{r}-0.1948 \\
0.5705 \\
0.8473 \\
0.8874 \\
0.8184 \\
0.0874 \\
0.9869 \\
\end{array}$ & $\left.\begin{array}{l}(0.1705) \\
(0.1561) \\
(0.2768) \\
(0.3676) \\
(0.2152) \\
(0.1209) \\
(0.2249)\end{array}\right)^{* *}$ & $\begin{array}{r}-0.2247 \\
0.3602 \\
1.6423 \\
1.8050 \\
1.4395 \\
0.0281 \\
1.1077 \\
\end{array}$ & $\begin{array}{l}(0.1361) \\
(0.1384)^{* *} \\
(0.4618)^{* *} \\
(0.4953)^{* *} \\
(0.3957)^{* *} \\
(0.0494) \\
(0.2836)^{* *}\end{array}$ & $\begin{array}{r}1.6804 \\
(1.3350)\end{array}$ & $\begin{array}{r}-0.4713 \\
(0.8838)\end{array}$ & $\begin{array}{r}4.5508 \\
\text { (Degrees of Freedom: 5) }\end{array}$ & 0.2538 \\
\hline $\begin{array}{c}\text { Other } \\
\text { Countries }\end{array}$ & $\begin{array}{c}\text { Greece } \\
\text { Zimbabwe } \\
\text { Jordan } \\
\text { Nigeria }\end{array}$ & $\begin{array}{l}0.4739 \\
0.1568 \\
0.0966 \\
0.1321\end{array}$ & $\begin{array}{l}(0.2130) \\
(0.1839) \\
(0.0839) \\
(0.2516)\end{array}$ & $\begin{array}{r}0.7564 \\
-0.2581 \\
0.1209 \\
0.1599 \\
\end{array}$ & $\begin{array}{l}(0.1304) \\
(0.1643) \\
(0.0868) \\
(0.1281)\end{array}$ & $\begin{array}{r}5.8727 \\
(3.7425)\end{array}$ & $\begin{array}{r}-2.7068 \\
(2.2894)\end{array}$ & $\begin{array}{r}0.9239 \\
\text { (Degrees of Freedom: 2) }\end{array}$ & 0.6650 \\
\hline
\end{tabular}

\section{B. Market Crash of October 1987 Excluded}

\begin{tabular}{|c|c|c|c|c|c|c|c|c|c|}
\hline & \multirow[t]{2}{*}{ Countries } & \multirow{2}{*}{\multicolumn{2}{|c|}{ Beta }} & \multirow{2}{*}{\multicolumn{2}{|c|}{ Co-kurtosis }} & \multicolumn{2}{|c|}{ Kraus-Litzenberger (1976) } & \multirow{2}{*}{$\begin{array}{c}\text { Lagrange Multiplier Test } \\
\text { Chi-Square }\end{array}$} & \multirow{2}{*}{$\begin{array}{l}\text { Adjusted } \\
R \text {-Square }\end{array}$} \\
\hline & & & & & & $\alpha_{1}$ & $\alpha_{3}$ & & \\
\hline $\begin{array}{c}\text { Latin } \\
\text { America }\end{array}$ & $\begin{array}{c}\text { Argentina } \\
\text { Brazil } \\
\text { Chile } \\
\text { Mexico } \\
\text { Colombia } \\
\text { Venezuela }\end{array}$ & $\begin{array}{r}0.1666 \\
0.5162 \\
0.3528 \\
0.7016 \\
0.2918 \\
-0.2442\end{array}$ & $\begin{array}{l}(0.4949) \\
(0.4163) \\
(0.1619) \\
(0.2279) \\
(0.1760) \\
(0.3084)\end{array}{ }^{*}$ & $\begin{array}{l}0.2133 \\
0.7534 \\
0.3237 \\
0.8043 \\
0.6116 \\
-0.8147\end{array}$ & $\begin{array}{l}(0.7550) \\
(0.5199) \\
(0.1736) \\
(0.2082) \\
(0.1610) \\
(0.4456)\end{array}{ }^{* *}$ & $\begin{array}{r}1.7905 \\
(2.8412)\end{array}$ & $\begin{array}{r}0.4485 \\
(1.8993)\end{array}$ & $\begin{array}{r}16.6484 \\
\text { (Degrees of Freedom: 4) }\end{array}$ & 0.1577 \\
\hline Asia & $\begin{array}{c}\text { India } \\
\text { Korea } \\
\text { Thailand } \\
\text { Taiwan } \\
\text { Malaysia } \\
\text { Pakistan } \\
\text { Philippines }\end{array}$ & $\begin{array}{r}-0.2515 \\
0.6272 \\
0.5644 \\
0.5603 \\
0.6575 \\
0.0634 \\
0.8921 \\
\end{array}$ & 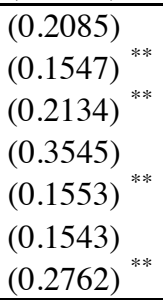 & $\begin{array}{r}-0.3811 \\
0.5860 \\
1.0384 \\
1.1592 \\
0.9467 \\
-0.0103 \\
1.5166\end{array}$ & $\begin{array}{l}(0.1980))^{*} \\
(0.1692)^{* *} \\
(0.3858) \\
(0.5767)^{*} \\
(0.2227)^{* *} \\
(0.0918) \\
(0.4910)^{* *}\end{array}$ & $\begin{array}{l}-1.1257 \\
(2.2127)\end{array}$ & $\begin{array}{r}1.7968 \\
(1.7209)\end{array}$ & $\begin{array}{r}2.9034 \\
\text { (Degrees of Freedom: 5) }\end{array}$ & 0.6427 \\
\hline $\begin{array}{c}\text { Other } \\
\text { Countries }\end{array}$ & $\begin{array}{c}\text { Greece } \\
\text { Zimbabwe } \\
\text { Jordan } \\
\text { Nigeria }\end{array}$ & $\begin{array}{l}0.4298 \\
0.2545 \\
0.1184 \\
0.1370\end{array}$ & $\begin{array}{l}(0.2383) \\
(0.1885) \\
(0.1089) \\
(0.2486)\end{array}$ & $\begin{array}{l}0.8158 \\
0.0290 \\
0.2471 \\
0.3049\end{array}$ & $\begin{array}{l}(0.2673) \\
(0.1611) \\
(0.1943) \\
(0.2023)\end{array}$ & $\begin{array}{r}6.8025 \\
(4.9611)\end{array}$ & $\begin{array}{r}-2.4800 \\
(2.8957)\end{array}$ & $\begin{array}{r}0.5460 \\
\text { (Degrees of Freedom: 2) }\end{array}$ & 0.7676 \\
\hline
\end{tabular}

Notes: $* *$ denotes significance at $1 \%$ and $*$ denotes significance at $5 \%$. Numbers in parentheses are standard errors. The three-moment CAPM estimated is $E\left(R_{i}\right)-r_{f}=\alpha_{1} \beta_{i}+\alpha_{3} \theta_{i}$ 
Table 10 GLS Estimates Based on Quadratic Market DGP

A. Market Crash of October 1987 Included

\begin{tabular}{|c|c|c|c|c|c|c|}
\hline Countries & $\overline{\alpha_{0, i}}$ & STD & $\overline{\alpha_{1, i}}$ & STD & $\overline{\alpha_{2, i}}$ & STD \\
\hline Greece & 0.8756 & 1.0062 & 0.4070 & 0.2289 & -0.0079 & 0.0243 \\
\hline Argentina & 4.4622 & $2.0655^{*}$ & -0.5873 & 0.4698 & -0.1372 & $0.0499^{* *}$ \\
\hline Brazil & 1.8761 & 1.7309 & 0.4292 & 0.3937 & -0.0830 & $0.0419^{*}$ \\
\hline Chile & 2.9395 & $0.6984^{* *}$ & 0.1738 & 0.1589 & -0.0432 & $0.0169^{* *}$ \\
\hline Mexico & 2.3858 & $1.2652^{*}$ & 0.7375 & $0.2878^{* *}$ & -0.0768 & $0.0306^{* *}$ \\
\hline India & 0.6787 & 0.8924 & -0.2418 & 0.2030 & -0.0051 & 0.0216 \\
\hline Korea & -0.4141 & 0.7225 & 0.6848 & $0.1643^{* *}$ & 0.0274 & 0.0175 \\
\hline Thailand & 2.1843 & $0.7407^{* *}$ & 0.4689 & $0.1685^{* *}$ & -0.0871 & $0.0179^{* *}$ \\
\hline Zimbabwe & 1.3116 & 0.8298 & 0.1954 & 0.1887 & 0.0198 & 0.0201 \\
\hline Jordan & 0.0273 & 0.4447 & 0.1274 & 0.1012 & -0.0025 & 0.0108 \\
\hline Colombia & 1.6706 & $0.7696^{*}$ & 0.1602 & 0.1750 & 0.0076 & 0.0186 \\
\hline Venezuela & 0.2366 & 1.3374 & -0.1325 & 0.3042 & 0.0353 & 0.0323 \\
\hline Taiwan & 2.3212 & $1.2062^{*}$ & 0.5610 & $0.2744^{*}$ & -0.0912 & $0.0292^{* *}$ \\
\hline Malaysia & 1.2512 & $0.6091^{*}$ & 0.5949 & $0.1386^{* *}$ & -0.0654 & $0.0147^{* *}$ \\
\hline Pakistan & 0.3395 & 0.6639 & 0.0800 & 0.1510 & 0.0064 & 0.0161 \\
\hline Philippines & 2.1227 & $0.8707^{* *}$ & 0.7180 & $0.1980^{* *}$ & -0.0239 & 0.0211 \\
\hline Nigeria & -0.4712 & 1.5865 & 0.2663 & 0.3609 & 0.0195 & 0.0384 \\
\hline \multicolumn{2}{|l|}{$R^{2}$} & 0.0732 & & & & \\
\hline
\end{tabular}

B. Market Crash of October 1987 Excluded

\begin{tabular}{|c|c|c|c|c|c|c|}
\hline Countries & $\alpha_{0, i}$ & STD & $\alpha_{1, i}$ & STD & $\alpha_{2, i}$ & STD \\
\hline Greece & 0.6960 & 1.0663 & 0.3845 & 0.2350 & 0.0077 & 0.0380 \\
\hline Argentina & 5.1883 & $2.1833^{* *}$ & -0.5468 & 0.4812 & -0.1971 & $0.0777^{* *}$ \\
\hline Brazil & 2.7666 & 1.8216 & 0.5044 & 0.4015 & -0.1580 & $0.0649^{* *}$ \\
\hline Chile & 2.7069 & $0.7381^{* *}$ & 0.1349 & 0.1627 & -0.0223 & 0.0263 \\
\hline Mexico & 1.6316 & 1.3266 & 0.6300 & $0.2924^{*}$ & -0.0105 & 0.0472 \\
\hline India & 0.5478 & 0.9459 & -0.2580 & 0.2085 & 0.0062 & 0.0337 \\
\hline Korea & -0.3603 & 0.7662 & 0.6990 & $0.1689^{* *}$ & 0.0223 & 0.0273 \\
\hline Thailand & 2.1431 & $0.7855^{* *}$ & 0.4383 & $0.1731^{* *}$ & -0.0819 & $0.0280^{* *}$ \\
\hline Zimbabwe & 1.6125 & $0.8766^{*}$ & 0.2351 & 0.1932 & -0.0064 & 0.0312 \\
\hline Jordan & 0.1652 & 0.4704 & 0.1422 & 0.1037 & -0.0143 & 0.0167 \\
\hline Colombia & 1.6537 & $0.8163^{*}$ & 0.1606 & 0.1799 & 0.0089 & 0.0291 \\
\hline Venezuela & -0.4197 & 1.4083 & -0.1956 & 0.3104 & 0.0911 & $0.0501^{*}$ \\
\hline Taiwan & 2.3138 & $1.2795^{*}$ & 0.5330 & $0.2820^{*}$ & -0.0889 & $0.0456^{*}$ \\
\hline Malaysia & 1.1875 & 0.6458 * & 0.5682 & $0.1423^{* *}$ & -0.0587 & $0.0230^{* *}$ \\
\hline Pakistan & 0.2249 & 0.7036 & 0.0690 & 0.1551 & 0.0161 & 0.0251 \\
\hline Philippines & 2.6773 & $0.9121^{* *}$ & 0.7731 & $0.2010^{* *}$ & -0.0711 & $0.0325^{* *}$ \\
\hline Nigeria & -0.6133 & 1.6825 & 0.2562 & 0.3708 & 0.0314 & 0.0599 \\
\hline \multicolumn{2}{|l|}{$R^{2}$} & 0.0565 & & & & \\
\hline
\end{tabular}

Notes: $* *$ denotes significance at $1 \%$ and $*$ denotes significance at $5 \%$.

The quadratic market DGP estimated is

$$
R_{i, t}-r_{f}=\alpha_{0, i}+\alpha_{1, i}\left(R_{m, t}-r_{f}\right)+\alpha_{2, i}\left(R_{m, t}-E\left(R_{m}\right)\right)^{2}+\varepsilon_{i, t}
$$


Table 11 GLS Estimates Based on Cubic Market DGP

A. Market Crash of October 1987 Included

\begin{tabular}{|c|r|l|r|l|l|l|l|l|}
\hline Countries & $\alpha_{0, i}$ & STD & $\alpha_{1, i}$ & STD & $\alpha_{2, i}$ & STD & $\alpha_{3, i}$ & STD \\
\hline Greece & 0.4772 & 1.0249 & 0.1095 & 0.2884 & 0.0442 & 0.0395 & 0.0045 & $0.0027^{*}$ \\
Argentina & 5.2017 & $2.1075^{* *}$ & -0.0352 & 0.5931 & -0.2340 & $0.0811^{* *}$ & -0.0084 & 0.0056 \\
Brazil & 2.4631 & 1.7675 & 0.8676 & $0.4975 *$ & -0.1598 & $0.0681 *$ & -0.0066 & 0.0047 \\
Chile & 2.8332 & $0.7172^{* *}$ & 0.0944 & 0.2018 & -0.0293 & 0.0276 & 0.0012 & 0.0019 \\
Mexico & 1.8950 & 1.2892 & 0.3711 & 0.3628 & -0.0126 & 0.0496 & 0.0056 & 0.0034 \\
India & 0.6731 & 0.9176 & -0.2460 & 0.2583 & -0.0044 & 0.0353 & 0.0001 & 0.0024 \\
Korea & -0.3786 & 0.7429 & 0.7113 & $0.2091 * *$ & 0.0228 & 0.0286 & -0.0004 & 0.0020 \\
Thailand & 1.9739 & $0.7579 *$ & 0.3118 & 0.2133 & -0.0596 & $0.0292 *$ & 0.0024 & 0.0020 \\
Zimbabwe & 1.6516 & $0.8446 *$ & 0.4492 & $0.2377 *$ & -0.0246 & 0.0325 & -0.0039 & 0.0022 \\
Jordan & 0.0526 & 0.4572 & 0.1463 & 0.1287 & -0.0058 & 0.0176 & -0.0003 & 0.0012 \\
Colombia & 1.4588 & $0.7877^{*}$ & 0.0021 & 0.2217 & 0.0353 & 0.0303 & 0.0024 & 0.0021 \\
Venezuela & -0.0436 & 1.3716 & -0.3417 & 0.3860 & 0.0720 & 0.0528 & 0.0032 & 0.0036 \\
Taiwan & 2.0629 & $1.2370 *$ & 0.3682 & 0.3481 & -0.0574 & 0.0476 & 0.0029 & 0.0033 \\
Malaysia & 1.1021 & $0.6241^{*}$ & 0.4836 & $0.1757 * *$ & -0.0459 & $0.0240 *$ & 0.0017 & 0.0016 \\
Pakistan & 0.2952 & 0.6825 & 0.0469 & 0.1921 & 0.0122 & 0.0263 & 0.0005 & 0.0018 \\
Philippines & 2.1892 & $0.8950 *$ & 0.7677 & $0.2519 * *$ & -0.0325 & 0.0345 & -0.0008 & 0.0024 \\
Nigeria & -0.6575 & 1.6301 & 0.1273 & 0.4588 & 0.0439 & 0.0628 & 0.0021 & 0.0043 \\
\hline$R^{2}$ & & 0.0807 & & & &
\end{tabular}

B. Market Crash of October 1987 Excluded

\begin{tabular}{|c|c|c|c|c|c|c|c|c|}
\hline Countries & $\alpha_{0, i}$ & STD & $\alpha_{1, i}$ & STD & $\alpha_{2, i}$ & STD & $\alpha_{3, i}$ & STD \\
\hline Greece & 0.9391 & 1.0482 & -0.3218 & 0.3640 & 0.0446 & 0.0400 & 0.0140 & 0.0056 \\
\hline Argentina & 4.9295 & $2.1802^{*}$ & 0.2052 & 0.7571 & -0.2364 & $0.0831^{* *}$ & -0.0149 & 0.0116 \\
\hline Brazil & 2.7323 & 1.8292 & 0.6039 & 0.6352 & -0.1632 & $0.0698^{*}$ & -0.0020 & 0.0097 \\
\hline Chile & 2.6681 & $0.7404^{* *}$ & 0.2477 & 0.2571 & -0.0282 & 0.0282 & -0.0022 & 0.0039 \\
\hline Mexico & 1.6378 & 1.3323 & 0.6122 & 0.4626 & -0.0096 & 0.0508 & 0.0004 & 0.0071 \\
\hline India & 0.4818 & 0.9482 & -0.0665 & 0.3293 & -0.0038 & 0.0362 & -0.0038 & 0.0050 \\
\hline Korea & -0.3585 & 0.7695 & 0.6940 & $0.2672^{* *}$ & 0.0225 & 0.0293 & 0.0001 & 0.0041 \\
\hline Thailand & 2.2904 & $0.7776^{* *}$ & 0.0104 & 0.2700 & -0.0596 & $0.0297^{*}$ & 0.0085 & $0.0041^{*}$ \\
\hline Zimbabwe & 1.4856 & $0.8729^{*}$ & 0.6036 & $0.3031 *$ & -0.0257 & 0.0333 & -0.0073 & 0.0046 \\
\hline Jordan & 0.2172 & 0.4701 & -0.0088 & 0.1632 & -0.0064 & 0.0179 & 0.0030 & 0.0025 \\
\hline Colombia & 1.8264 & $0.8049^{* *}$ & -0.3412 & 0.2795 & 0.0351 & 0.0307 & 0.0099 & $0.0043^{*}$ \\
\hline Venezuela & -0.5277 & 1.4110 & 0.1182 & 0.4900 & 0.0747 & 0.0538 & -0.0062 & 0.0075 \\
\hline Taiwan & 2.5197 & $1.2715^{*}$ & -0.0650 & 0.4415 & -0.0576 & 0.0485 & 0.0118 & $0.0068^{*}$ \\
\hline Malaysia & 1.2730 & 0.6440 * & 0.3199 & 0.2236 & -0.0458 & $0.0246^{*}$ & 0.0049 & 0.0034 \\
\hline Pakistan & 0.2021 & 0.7063 & 0.1353 & 0.2453 & 0.0127 & 0.0269 & -0.0013 & 0.0038 \\
\hline Philippines & 2.9147 & $0.8906^{* *}$ & 0.0835 & 0.3093 & -0.0351 & 0.0340 & 0.0136 & $0.0047^{* *}$ \\
\hline Nigeria & -0.5281 & 1.6881 & 0.0085 & 0.5862 & 0.0443 & 0.0644 & 0.0049 & 0.0090 \\
\hline \multicolumn{2}{|l|}{$R^{2}$} & 0.0727 & & & & & & \\
\hline
\end{tabular}

Notes: $* *$ denotes significance at $1 \%$ and $*$ denotes significance at $5 \%$.

The cubic market DGP estimated is

$$
R_{i, t}-r_{f}=\alpha_{0, i}+\alpha_{1, i}\left(R_{m, t}-r_{f}\right)+\alpha_{2, i}\left(R_{m, t}-E\left(R_{m}\right)\right)^{2}+\alpha_{3, i}\left(R_{m, t}-E\left(R_{m}\right)\right)^{3}+\varepsilon_{i, t}
$$




\section{List of other working papers:}

1999

1. Yin-Wong Cheung, Menzie Chinn and Ian Marsh, How do UK-Based Foreign Exchange Dealers Think Their Market Operates?, WP99-21

2. Soosung Hwang, John Knight and Stephen Satchell, Forecasting Volatility using LINEX Loss Functions, WP99-20

3. Soosung Hwang and Steve Satchell, Improved Testing for the Efficiency of Asset Pricing Theories in Linear Factor Models, WP99-19

4. Soosung Hwang and Stephen Satchell, The Disappearance of Style in the US Equity Market, WP99-18

5. Soosung Hwang and Stephen Satchell, Modelling Emerging Market Risk Premia Using Higher Moments, WP99-17

6. Soosung Hwang and Stephen Satchell, Market Risk and the Concept of Fundamental Volatility: Measuring Volatility Across Asset and Derivative Markets and Testing for the Impact of Derivatives Markets on Financial Markets, WP99-16

7. Soosung Hwang, The Effects of Systematic Sampling and Temporal Aggregation on Discrete Time Long Memory Processes and their Finite Sample Properties, WP99-15

8. Ronald MacDonald and Ian Marsh, Currency Spillovers and Tri-Polarity: a Simultaneous Model of the US Dollar, German Mark and Japanese Yen, WP99-14

9. Robert Hillman, Forecasting Inflation with a Non-linear Output Gap Model, WP99-13

10. Robert Hillman and Mark Salmon, From Market Micro-structure to Macro Fundamentals: is there Predictability in the Dollar-Deutsche Mark Exchange Rate?, WP99-12

11. Renzo Avesani, Giampiero Gallo and Mark Salmon, On the Evolution of Credibility and Flexible Exchange Rate Target Zones, WP99-11

12. Paul Marriott and Mark Salmon, An Introduction to Differential Geometry in Econometrics, WP99-10

13. Mark Dixon, Anthony Ledford and Paul Marriott, Finite Sample Inference for Extreme Value Distributions, WP99-09

14. Ian Marsh and David Power, A Panel-Based Investigation into the Relationship Between Stock Prices and Dividends, WP99-08

15. Ian Marsh, An Analysis of the Performance of European Foreign Exchange Forecasters, WP99-07

16. Frank Critchley, Paul Marriott and Mark Salmon, An Elementary Account of Amari's Expected Geometry, WP99-06

17. Demos Tambakis and Anne-Sophie Van Royen, Bootstrap Predictability of Daily Exchange Rates in ARMA Models, WP99-05

18. Christopher Neely and Paul Weller, Technical Analysis and Central Bank Intervention, WP9904

19. Christopher Neely and Paul Weller, Predictability in International Asset Returns: A Reexamination, WP99-03

20. Christopher Neely and Paul Weller, Intraday Technical Trading in the Foreign Exchange Market, WP99-02

21. Anthony Hall, Soosung Hwang and Stephen Satchell, Using Bayesian Variable Selection Methods to Choose Style Factors in Global Stock Return Models, WP99-01

\section{8}

1. Soosung Hwang and Stephen Satchell, Implied Volatility Forecasting: A Compaison of Different Procedures Including Fractionally Integrated Models with Applications to UK Equity Options, WP98-05

2. Roy Batchelor and David Peel, Rationality Testing under Asymmetric Loss, WP98-04

3. Roy Batchelor, Forecasting T-Bill Yields: Accuracy versus Profitability, WP98-03 
4. Adam Kurpiel and Thierry Roncalli, Option Hedging with Stochastic Volatility, WP98-02

5. Adam Kurpiel and Thierry Roncalli, Hopscotch Methods for Two State Financial Models, WP98-01 